Taking a Different Point of View:

An Exploration of Culture and Reflecting Using Outsider Perspectives

\author{
Felicity Fangtan Miao \\ Hong Kong
}

Bachelor of Arts, Stanford University, 2004

Master of Arts, Stanford University, 2004

Master of Arts, University of Virginia, 2010

A Dissertation presented to the Graduate Faculty of the University of Virginia in Candidacy for the Degree of Doctor of Philosophy

\title{
Department of Psychology
}

University of Virginia

August 2013 


\begin{abstract}
The self-immersed perspective, or self-perspective (visualizing an event through one's own eyes) has been shown to lead to rumination, while the self-distanced perspective, or observer perspective (visualizing an event by watching the self from a distance) allows individuals to come to an understanding or clarity of their internal states (Kross \& Adyuk, 2011). What is missing from this program of research however, is a third, commonly used perspective, “stepping into the other person's shoes"-perspective of a close other (visualizing an event from a close friend's perspective) that has been shown to be prevalent in Asian contexts. The current study addressed two main questions: (1) What is the nature of spontaneous perspective-taking in Indians and European Americans, and (2) How does a close other perspective compare to the much studied observer perspective in terms of generating reconstrual and reducing emotional distress? Indian participants were more likely than European Americans to report using outsider perspectives (observer perspective and close other perspective), feeling more positive affect, and having engaged in more reconstruing than recounting after analyzing their feelings towards a conflict event. Experimental manipulations of observer perspective and close other perspective did not reveal any differences in efficacy for European Americans, therefore implying adoption of either one of the strategies is an ideal approach to generate insight and understanding when self-reflecting on a conflict event. However, the findings on whether these strategies are beneficial for Indian participants are mixed. As a whole, these findings are the first to document cultural differences between Indians and European Americans when reflecting about a conflict event and illustrate to a degree, the efficacy of outsider perspectives in eliciting relatively more reconstrual thoughts and reducing emotional distress.
\end{abstract}




\section{Table of Contents}

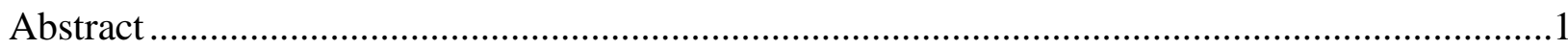

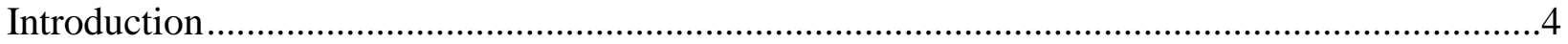

Gaining Insight into Positive and Negative Events ......................................................5

Paradox of Negative Events ...............................................................................6

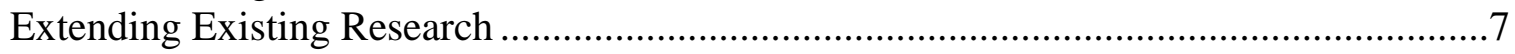

Literature Review and Theoretical Background .......................................................... 10

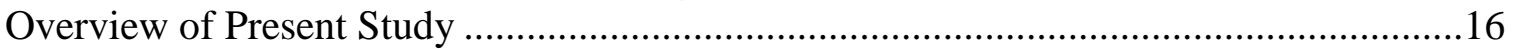

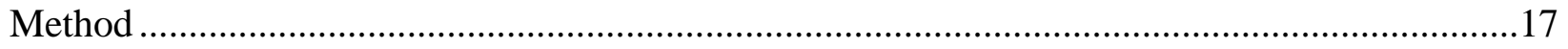

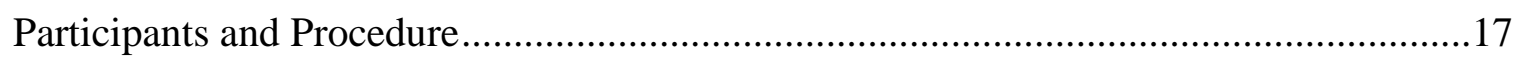

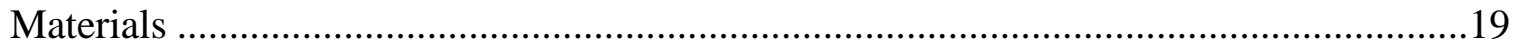

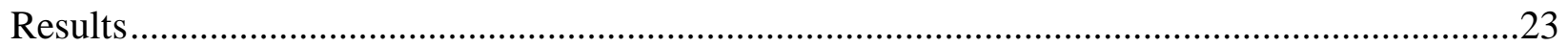

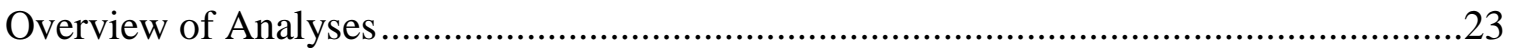

Cultural Differences in Spontaneous Perspective-Taking .............................................23

Summary of Findings for Cultural Differences in Spontaneous Perspective-Taking........27

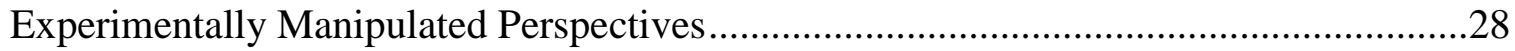

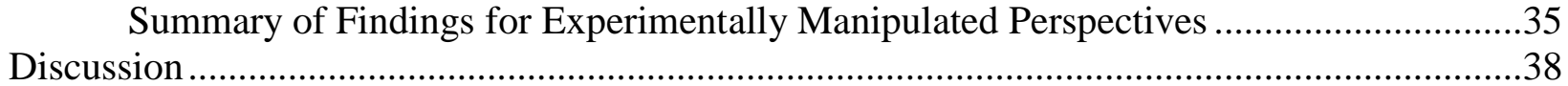

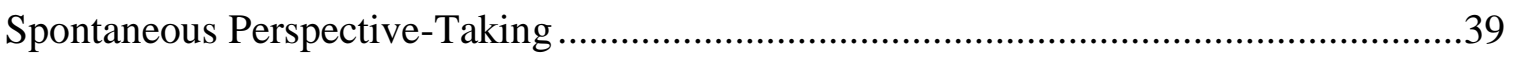

Experimentally Manipulated Perspectives .............................................................. 41

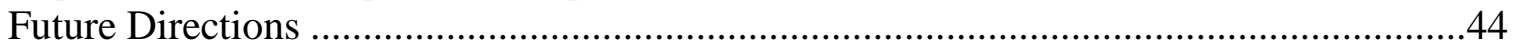

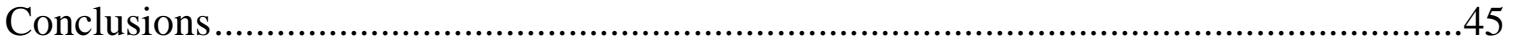

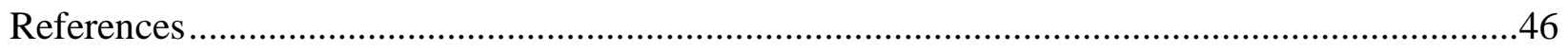

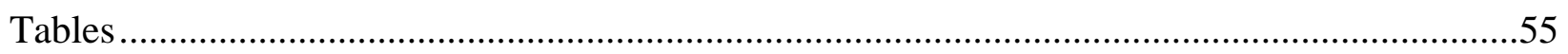

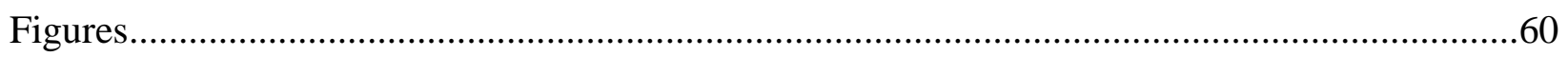




\section{Taking a Different Point of View:}

An Exploration of Culture and Reflecting Using Outsider Perspectives

The unexamined life isn't worth living. - Socrates

Philosophers both in the days gone by and now have espoused the notion that examination of one's life is a worthy pursuit. Though modern philosophers are unlikely to be as harsh as Socrates, many consider an appropriately examined life, a more fulfilling life (e.g., Tiberius, 2008). This process of intellectual examination and evaluation of one's thoughts, feelings, and behavior is defined as self-reflection (Grant, Franklin, \& Langford, 2002; Trapnell \& Campbell, 1999). Self-reflection is distinct from rumination (a neurotic examination and evaluation of one's thoughts, feelings and behaviors; Joireman, Parrott, \& Hammersla, 2002; Treynor, Gonzalez, \& Nolen-Hoeksema, 2003) and is also distinct from life review. While life review involves the intellectual examination and evaluation of one's thoughts, feelings, and behavior, it differs in the scope with which it encompasses. As the name life review suggests, this construct encompasses large sections of one's life (e.g., career achievements), whereas selfreflection encompasses small sections of one's life (e.g., argument with spouse earlier today) (Staudinger, 2001).

It may be easy for a lay person to assume that engaging in lots of self-reflection would result in the more fulfilling life that philosophers describe. However, there were no psychological well-being differences between those who engaged in large amounts of selfreflection compared to those who engaged in small amounts of self-reflection (Lyke, 2009; 
Harrington \& Loffredo, 2011). Only those who gained good insight into the issues they pondered reaped benefits in the form of higher psychological well-being. Although the definition of insight varies by discipline (e.g., cognitive vs. clinical) and by researcher, many of the definitions point to individuals reaching an "aha" moment where some greater level of understanding or clarity of their internal states (i.e., thoughts, feelings, and behaviors) is achieved (e.g., Grant et al., 2002; Lyke, 2009). Therefore using this definition, it is possible to see how insight may operate independently of self-reflection. Some individuals may achieve good insight either after a period of extensive self-reflection, but others may achieve insight immediately without undergoing a process of self-reflection. This being said, there are at least two reasons why attempting to gaining good insight into every issue may not be the wisest thing to do.

\section{Gaining Insight into Positive and Negative Events}

First, we assume that we know the reasons behind our thoughts, feelings, and behaviors and can therefore easily gain insight into any issue we chose to self-reflect on, but this is not the case. Because there are a number of domains where the mind operates efficiently outside of conscious awareness (perception, attention, learning, evaluation, emotion, and motivation) (see Wilson \& Dunn, 2004 for review), we actually do not have an accurate understanding of all the reasons behind our thoughts, feelings, and behaviors. Individuals generate reasons that are consciously available and these tend to be reasons that are consistent with their personal or

cultural theories (Nisbett \& Wilson 1977; Wilson, 2002). Wilson (2002; 2009; Wilson \& Dunn, 2004) suggests that we attempt to overcome these limitations by first trying to be objective observers of our own behavior, and second, try to learn about ourselves by seeing ourselves through the eyes of other people. 
Despite the fact that we do not have full access to the reasons behind our thoughts, feelings, and behaviors, engaging in self-reflection can lead to insights that are beneficial to our emotional health. Pennebaker (1997) found that individuals who were able to command a coherent version of a negative emotional episode reduced their emotional distress because they came to an understanding of the negative event. This finding fits in with Wilson and Gilbert's (2008) AREA model where they predict that after attending (A) and reacting (R) to an event, individuals try to explain (E) the event and ultimately adapt (A) to the event. The AREA model makes differential predictions for positive and negative events. For negative events, it is useful to attempt to gain insight into the situation in order to resolve the negative experience, but for positive events, attempts to gain insight into why an event was positive would ultimately lead to the experience being less pleasurable. Therefore, the AREA model indicates that attempts to gain insight from a situation should be focused only on negative events.

\section{Paradox of Negative Events}

Although Pennebaker's (1997) finding on insight and reducing emotional distress has been replicated many times in the literature (see Pennebaker \& Chung, 2007 and Smyth, 1998 for reviews), there is an equally large body of work presenting the opposite finding. Sometimes, individuals' attempts to explain and adapt to a negative event actually puts them into an endless cycle of negative thinking that does nothing to alleviate emotional distress (Nolen-Hoeksema, Wisco, \& Lyubomirsky, 2008, and see Mor \& Winquist, 2002 and Watkins, 2008 for rumination reviews). It seems that one explanation for this paradox lies in the type of self-perspective individuals adopt when thinking about negative events. A program of work by Kross and his colleagues (see Kross \& Adyuk, 2011 for quick overview) explain the paradox by examining differences between the self-immersed perspective and self-distanced perspective. In a self- 
immersed perspective, individuals visualize an event through their own eyes (first-person perspective). When they try to gain insight into why the situation occurred, they are unsuccessful as the individual is usually focused on recounting the event and therefore only takes a narrow perspective on the situation. Recounting involves thinking about the specifics of what happened and blaming the partner without providing reasons. The repeated recounting of the event is akin to what happens in rumination-a vicious cycle of repetitive negative thought. Because no insight has been gained into the situation, the event remains a source of negative distress. It is important to note that it is the tandem effect of visualizing an event through one's own eyes and also recounting an event that makes this an ineffective way to gain insight into a negative situation. Yet in a self-distanced perspective, individuals visualize the event by distancing themselves from the situation and observing themselves (third-person perspective), such as adopting the "perspective of a fly on the wall". Individuals' attempts to gain insight into why the situation occurred are usually much more likely to be successful as the distanced focus allows individuals to take a broad perspective and reconstrue the event in ways that were not originally accessible. Reconstruing involves having metacognitive thoughts that lead one to have new insights into the situation and achieve closure. Being able to come to an understanding of what happened is an important step in adapting to and ultimately resolving a negative event. Again, it is important to note that it is the tandem effect of taking a distanced stance on the situation and also reconstruing an event that makes this an effective way to resolve a negative event.

\section{Extending Existing Research}

This dissertation is intended to build upon the existing work on how different types of perspective can contribute to alleviating negative distress. First, I propose a new approach to the existing work, by studying an additional third perspective alongside the two already investigated 
(self-immersed and self-distanced) — the perspective of a close other. The close other perspective involves seeing a given situation from a close person's perspective (e.g., friend). By viewing the situation via the "eyes" of a friend, the close other perspective is another method in which to generate distance from the self. The close other perspective is common among lay people intuitions ("stepping into the other person's shoes") and has been described extensively in the perspective-taking literature (e.g., Epley \& Caruso, 2008; Hodges, Clark, \& Myers, 2011), as well as in one of the most commonly used perspective-taking scales: perspective-taking items from the Interpersonal Reactivity Index (Davis, 1983).

Kross and colleagues' self-distanced perspective utilizes the self to distance from the self while the close other perspective utilizes a friend to achieve distancing from the self. Kross and colleagues have operationalized the self-distanced perspective as a third-person perspective, or the perspective of an observer: "watch the conflict unfold as if it were happening all over again to the distant you" (Kross, Ayduk, \& Mischel, 2005). This instruction makes it clear that one needs to both think of the self for information about what the self is doing in the situation and also transcend oneself by becoming one's own observer. Indeed, George Herbert Mead (1913) who made valuable insights from the work of William James (1890) wrote about this process of "becoming other to oneself". Mead called these dual selves "I" and "me", where "I" is the subject self while "me" is the object self (the reflecting self).

On the surface, the outcome of both the self-distancing perspective and the close other perspective seem to be identical; they both lead to taking a distanced stance from the situation, enabling reconstruing and reduction in emotional distress. However, the process differences between the self-distanced perspective and the close other perspective may actually lead to differential outcomes. Directing participants to focus on themselves has been shown to enhance 
emotional reactions, particularly when the situation is negative (see Mor \& Winquist, 2002 for review.) Furthermore, this finding is also supported in the depression literature where considering others leads to less negative thinking than when considering the self whether for attribution style, interpretation, or predictions for the future (see also Wisco, 2009 for review). Therefore, the slightly greater weight of self in the process of undergoing the self-distancing perspective may undo some of the positive benefits of taking a distanced stance. Because no studies have examined the close other perspective, this study will be the first to be able to compare the impact of the greater weight of self in the self-distancing perspective versus the close other perspective.

In order to be able to better distinguish between the two outsider perspectives - the selfdistanced perspective involving the self as an observer versus the distanced perspective involving a close other, I will use the terms "observer perspective" and "close other perspective" respectively, and refer to the existing self-immersed perspective by Kross and colleagues as the “self-perspective".

Second, because virtually all the work on types of perspectives and alleviating negative distress has been on European Americans, I propose to also study Asians as previous cultural psychology research indicates that East Asians tend to give a privileged position to outsider perspectives (e.g., Cohen \& Gunz, 2002; Cohen, Hoshino-Browne, \& Leung, 2007; Wu \& Keysar, 2007). Interestingly, findings in cultural psychology have documented evidence for East Asians giving greater primacy to the observer perspective (e.g, Cohen \& Gunz, 2002; Cohen et al., 2007) and also for the close other perspective (e.g., Wu \& Keysar, 2007), relative to the selfperspective. Because no study has directly compared the two types of outsider perspectives, it is 
unclear whether Asians will be more likely to spontaneously adopt an observer perspective or close other perspective when self-reflecting about negative events.

\section{Literature Review and Theoretical Background}

In this section, I will first review the existing body of work on self-immersed vs. selfdistanced perspectives by Kross and colleagues and one possible theoretical explanation (Construal-Level Theory of Psychological Distance) for the findings. Then, I will review what is known about perspective-taking. Perspective-taking is commonly thought of as "stepping into someone else's shoes" and is the task that individuals attempt to accomplish when they are trying to adopt a close other perspective. Because all the different types of perspectives being examined in the current study are relevant to the self, I will briefly review the literature on self-focused attention and emotion. Finally, I will review the cultural psychology research on the primacy of outsider perspectives in East Asian contexts relative to the primacy of insider perspectives in European American contexts.

Self-immersed (self) and self-distanced (observer) perspectives. The self-immersed and self-distanced perspectives have their origins in a study by Nigro and Neisser (1983) on visual perspectives in autobiographical memory. Nigro and Neisser found that participants spontaneously recalled events either from a field perspective (self-perspective) or observer perspective. Kross et al. (2005) found that if participants were instructed to adopt one of these two perspectives when analyzing feelings from an anger eliciting event, those who adopted a self-distanced (observer) perspective reported lower levels of emotional distress compared to those who adopted a self-immersed (self) perspective (see also Ayduk \& Kross, 2008; Ayduk \& Kross, 2010 Study 2; Grossmann \& Kross, 2010; Kross, Duckworth, Ayduk, Tsukayama, \& Mischel, 2011; Mischkowski, Kross, \& Bushman, 2012; Verduyn, Van Mechelen, Kross, Chezzi, 
\& Van Bever, 2012 for replications of this finding for anger events). This strategy has also been shown to be effective when analyzing feelings about a sad event (Kross \& Ayduk, 2008; Kross, Gard, Deldin, Clifton, \& Ayduk, 2012; Verduyn et al., 2012) or a rejection event (Ayduk \& Kross, 2010 Study 1). The self-distanced (observer) perspective works in reducing emotional distress when participants also engage in abstract thinking (reconstruing the event to gain insight and achieve closure). Likewise, the self-immersed (self) perspective fails in reducing emotional distress when participants also engage in concrete thinking (recounting an event in full detail and assigning blame attributions to partner). In all of the studies reported by Kross and colleagues, concrete and abstract thinking have been shown to mediate the relationship between type of perspective taken and emotional distress (see Kross et al., 2005 for the first reported mediation finding). Interestingly, analyzing feelings about a positive event using a self-distanced perspective led to a shorter positive emotional episode (Verduyn et al., 2012), which is in line with Wilson and Gilbert's (2008) AREA model.

Adopting a self-distancing perspective has been shown to not only have immediate effects on dampening emotions, but to also have buffering effects up to 1 week later (Kross \& Ayduk, 2008). Individuals who naturally or spontaneously adopt a self-distancing perspective in thinking about their own lives receive the same benefit as those who adopt a self-distancing perspective when prompted (Ayduk \& Kross, 2010; Verduyn et al., 2012). Self-distancing has benefits not only for healthy individuals, but also for depressed individuals (Kross \& Ayduk, 2008; Kross \& Ayduk, 2009; Kross et al., 2012). Furthermore, the positive benefits also extend to children (Kross et al., 2011). Only one study to date has documented the cultural differences in self-distancing. Russians (who are relatively more interdependent) compared to European 
Americans naturally adopt a self-distancing perspective more and consequently feel less emotional distress (Grossmann \& Kross, 2010).

Psychological distance. Psychological distance is one possible explanation for the efficacy of the observer perspective relative to the self-perspective. The Construal-Level Theory of Psychological Distance (Trope \& Liberman, 2010) suggests that psychological distance, whether in the form of spatial, temporal, social, or hypothetical distance, impacts the way individuals predict, evaluate, and act. When an object or event is removed from the self, it is construed at a higher or more abstract level (vs. lower or more concrete level). Therefore, psychological distance causes people to "focus on the forest", while psychological nearness causes people to "focus on the trees". And because the relationship between psychological distance and construal level is bidirectional, higher or more abstract construals also lead to individuals perceiving greater psychological distance.

A number of studies have revealed how the social distance between the third-person and first-person perspectives is related to a higher (vs. lower) level of construal. Nigro and Neisser (1983) found that individuals tended to recall distant events from a third-person perspective and recent events from a first-person perspective. Libby and Eibach (2002, Study 4) found that imagining performing an activity from a third-person perspective produced less vivid and rich reports of the imagined activity than from a first-person perspective. Similarly, Sutin and Robbins (2010) found that third-person memories were less vivid and detailed compared to firstperson memories. Van Boven, Kane, McGraw, and Dale (2010) found that individuals who described events emotionally versus neutrally perceived those events to be less psychologically distant. Kross and colleagues have shown the concrete and abstract thoughts do mediate the 
relationship between type of perspective-taking and emotional distress (e.g., Kross et al., 2005) but no studies to date have measured psychological distance.

Perspective-taking. Perspective-taking refers to the cognitive ability to imagine the world from another point of view. Although most researchers use the term to refer to an individual imagining how another person feels in a certain situation (see many examples in reviews of perspective-taking: Epley \& Caruso, 2008; Hodges et al., 2011), it has also been used to refer to an individual imagining how they would feel in another person's situation (cf. Batson, Early, \& Salvarani, 1997; Davis, Conklin, Smith, \& Luce, 1996; Davis et al., 2004).

Perspective-taking has been found to confer many benefits, including increased social coordination (e.g., Galinsky, Ku, \& Wang, 2005), psychological altruism (e.g., Batson et al., 2003), and reduction in prejudice and stereotypes (e.g., Galinsky \& Moskowitz, 2000). (See Hodges et al., (2011) for a review of the variety of benefits perspective-taking affords.) Despite these benefits, perspective-taking is a deliberate process that requires individuals to make an effort to activate a perspective that is different from their own (see Epley \& Caruso, 2008). The process can be made more automatic if one undergoes enough practice: the default operating assumption for individuals from collectivistic contexts is to place more primacy on other's perspectives (Cohen \& Gunz, 2002; Cohen et al., 2007; Wu \& Keysar, 2007)

Research on the process of perspective-taking indicates that individuals first think about their own perspective, and then gradually adjust their own perspective to match the other person's perspective. Participants who were asked to take the perspective of a target person were more likely to ascribe the target with traits that participants themselves had rated as selfdescriptive (Davis et al., 1996). Interestingly, the degree of self-other overlap was reduced when participants were asked to complete a distracting memory task before engaging in perspective- 
taking (Davis et al., 1996, Study 2). A more recent study shows that participants where quicker to identify how another person's perspective were similar to their own compared to dissimilar perspectives (Epley, Keysar, Van Boven, \& Gilovich, 2004, Study 2). In a study that captured perspective-taking behavior (via an eye tracker), participants who were asked to adopt the perspective of their partner in a communication game first focused on objects that they themselves could see (but their partner could not see) before focusing on the mutually viewed objects (Keysar, Barr, Balin, \& Brauner, 2000).

Self-focused attention and emotion. When individuals become self-aware, they are more likely to pay greater attention to subsequent stimuli and react more strongly than those who do not experienced a heightened sense of self. In a classic study by Fenigstein (1979), selfawareness was activated with the presence of a mirror. Participants who saw themselves in the mirror responded had greater affective responses to either the positive or negative personality feedback provided by an experimenter, though the effect was particularly strong for negative personality feedback. In an extensive meta-analysis of over 200 studies, Mor and Winquist (2002) found that the relationship between self-focused attention and negative affect has a weighted mean effect size of about .50 (Cohen's $d$ ), illustrating that these effects are moderate and should be easily observed.

Culture, thinking and perspective-taking. East Asians tend to give a privileged position to the observer perspective over the self-perspective (Cohen et al., 2007). For example, East Asians are more likely to recall a life event from a third-person perspective (observer perspective) than a first-person perspective compared to Westerners (Cohen \& Gunz, 2002). However, it is important to note that this is a tendency and not a rule. The tendency to use a third-person perspective when recalling memories is driven by a functional response to the 
demands of the situation. Individuals from interdependent contexts are focused on fitting in, adjusting themselves to the situation, and not standing out (Heine, Lehman, Markus, \& Kitayama, 1999; Morling, Kitayama, \& Miyamoto, 2002). Therefore, when one is at the center of attention or at the center of a scene, adopting an observer perspective allows one to better fit in with one's cultural goals. There is also evidence that East Asians also give a privileged position to the close other perspective. A clever experiment by Wu and Keysar (2007) revealed that the desire to adjust to others and the situation results in Chinese participants being more accurate and quicker to respond compared to Westerners when explicitly asked to take the perspective of another during a perspective-taking communication game. Furthermore, Chinese-English bilingual participants performed differently on the above perspective-taking communication game depending on whether they had been primed with icons that represent Chinese culture or Western culture (Luk, Xiao, \& Cheung, 2012). In line with previous findings, participants who were primed to engage in a Chinese mindset were more accurate in the perspective-taking task.

The primacy of outsider perspectives by East Asians may also be explained by the tendency to prefer holistic versus analytic types of thinking. Perceptually, East Asians prefer to attend to the entire field, including the relationships between the focal object and the field, whereas Westerners prefer to attend to the focal object (e.g., Miyamoto, Nisbett, \& Masuda, 2006). Conceptually, East Asians prefer dialectical reasoning, where concepts are interrelated, and contradiction and change are expected and tolerated, whereas Westerners prefer analytic reasoning, where conclusions are derived from using formal rules and logic (e.g., Peng \& Nisbett, 1999). (See also Nisbett, Peng, Choi, \& Norenzayan, 2001 for a review of these cultural differences in thinking and their origins.) 


\section{Overview of Present Study}

In the present study, I examined two key questions regarding (1) how different types of perspectives are used in different cultural contexts and (2) the efficacy of the close other perspective relative to the observer perspective. First, what is the nature of spontaneous perspective-taking in Asians and European Americans when thinking about a negative emotional event? As reviewed above, much of the work has focused on European Americans. There is reason to believe that Asians will naturally use outsider perspectives (observer and close other perspective) more and the self-perspective less when compared to European Americans, but this remains to be documented.

Second, is the close other perspective more efficacious than the observer perspective in generating reconstrual and reducing emotional distress when analyzing feelings for negative events? Both perspectives invite removing the self from the situation, but the observer perspective involves oneself stepping back and observing the self, while the close other perspective involves observing the self from the perspective of a close individual (e.g., friend). Given that existing research by Kross and colleagues has shown that greater removal of the self from the situation best engenders reconstruing and reductions in emotional distress, will the slightly greater weight of the self in the observer perspective be less efficacious in generating reconstrual and reducing emotional distress than the close other perspective?

In addition to answering the above two key questions, I will also seek to replicate previous findings where thought content has been shown to mediate the relationship between type of perspective taken and emotional outcomes. This will be the first study to experimentally manipulate the close other perspective and compare it to the observer perspective. Together, the 
answers to these two questions will provide a more complete picture of the phenomenology of how Asians and European Americans self-reflect about negative events.

\section{Method}

\section{Participants and Procedure}

Participants were recruited from Amazon's Mechanical Turk (MTurk) website (www.mturk.com). MTurk offers a participant pool that is significantly more diverse than American college samples and data that is of comparable quality compared to other internet samples (Buhrmester, Kwang, \& Gosling 2011). Numerous comparisons of mTurk data with laboratory data seem to suggest the two are often comparable in quality (Mason \& Suri, 2012). Although participants on the website are from all over the world, the majority of them are from the USA or India (Mason \& Suri, 2012). Therefore, only American or Indian ${ }^{1}$ participants were recruited on mTurk. Two hundred and eighty Americans and 270 Indians responded to the request to complete a 10 minute thoughts and feelings survey with compensation of $\$ 0.50$ USD. Of the American participants, 67 participants identified with a cultural background other than White/European American and were excluded. Furthermore, in order to ensure that all European Americans were of the same background, an additional 7 participants were excluded for not being born and raised in the United States, leaving a total of 206 European American participants. Finally, 5 participants were excluded from the analysis because their essays (see below for details) revealed they did not follow instructions. Ultimately, 201 European Americans participants remained in the study ( 84 female, 109 male, 8 did not specify; $M_{\text {age }}=32.12$ years, $\left.S D=11.11 ; M_{\text {years of education }}=15.39, S D=2.39\right)$. Of the 270 Indian participants, 81 participants

\footnotetext{
${ }^{1}$ Previous work has revealed that Indian participants subscribe to the conjoint model of agency (Savani, Markus, \& Conner, 2008) that also describes East Asians, where "actions are responsive to obligations and expectations of others, roles, and situations; preferences, goals, and intentions are interpersonally anchored" (Markus \& Kitayama, 2003, p. 7).
} 
were excluded from the analysis because their essays revealed they did not follow study instructions. $^{2}$ A total of 199 Indian participants remained in the study (81 female, 109 male, 9 did not specify; $M_{\text {age }}=30.53$ years, $\left.S D=9.33 ; M_{\text {years of education }}=17.38, S D=2.55\right)$.

Participants were randomly assigned to one of four essay conditions: self, observer, close other, or spontaneous. Participants were asked to identify a time when they experienced conflict with a romantic partner or close friend. Then, they were directed to think and write about the reasons behind their feelings. For the self, observer, and close other conditions, participants were given descriptions of the perspective they were assigned and were asked to maintain that perspective as they wrote about their feelings. For the spontaneous condition, participants simply wrote their stream of thoughts without any explicit direction about any particular type of perspective to maintain. After the essay task, participants indicated (1) how they felt in the moment with words selected from the affective circumplex; (2) the extent to which they adopted self, observer, or close other perspectives when their analyzed their own feelings in the essay task; (3) how much they agreed with statements about their thought contents; (4) perceptions of the degree of psychological distance they felt from the event they identified; (5) how much they agreed with statements concerning emotional reactivity; and (6) the extent to which the conflict event is still salient in their memory.

Participants' stream of thought essays were analyzed for first person singular pronouns (e.g., I, me, my) and third person singular pronouns (e.g., she, he) with the Linguistic Inquiry and Word Count (LIWC; Pennebaker, Booth, \& Francis, 2007). The program counts words of interest expressed as a percentage of the total number of words. First person singular pronouns

\footnotetext{
${ }^{2}$ Although participants were asked to write about a conflict event, the excluded participants wrote about positive times in their life, clearly indicating that they did not follow the study instructions.
} 
and third person singular pronouns may be another method in which to identify whether

participants took a self-perspective or outsider perspective when analyzing their feelings from a conflict event. The length of participants' written essays was also recorded as a measure of ontask behavior.

\section{Materials}

Self-reflection instructions. Participants were asked to recall an anger experience with the following recall prompt (Kross et al., 2005):

No matter how well two people get along, there are times when they experience conflict: they do things that annoy each other, get into fights because they're in bad moods, or argue over major decisions. Take a few moments right now to think about times in your past when you experienced conflict with a romantic partner or close friend. As you think about these conflicts, try to identify one that was the most stressful, a time when you became truly enraged at your partner or friend. Although it may be difficult, most people can usually remember at least one incident. Take your time as you try to do this.

Participants then received a prompt depending on the condition they were assigned to. Each

prompt was designed to guide each participant to think about their feelings in the conflict situation using either the self-perspective, observer perspective, close other perspective, or no specific instruction (spontaneous condition). Participants were instructed to allow themselves some time to ponder the event, letting their deepest thoughts and feelings run through their mind before writing down their stream of thoughts.

Self-perspective: Now close your eyes. Go back to the time and place of the experience you just recalled and see the scene in your imagination. Now see the experience unfold through your own eyes as if it were happening to you all over again. Replay the event as it unfolds in your imagination through your own eyes. Take a few moments to do this. As you continue to watch the situation unfold through your own eyes, try to understand your feelings. Why did you have those feelings? What were the underlying causes and reasons?

Observer perspective: Now close your eyes. Go back to the time and place of the experience you just recalled and see the scene in your imagination. Now take a few steps back. Move away from the situation to a point where you can now watch the event unfold from a distance and see yourself in the event. As you do this, focus on what has now become the distant you. Now watch the experience unfold as if it were happening to the 
distant you all over again. Replay the event as it unfolds in your imagination as you observe your distant self. Take a few moments to do this. As you continue to watch the situation unfold to your distant self, try to understand his or her feelings. Why did s/he have those feelings? What were the underlying causes and reasons?

Close other perspective: Now close your eyes. Go back to the time and place of the experience you just recalled and see the scene in your imagination. Now think of a close friend who was not involved in the experience you just recalled and keep him/her in mind. Now watch the experience unfold from your close friend's point of view. Imagine how s/he would feel if they were watching the experience you had unfold in front of them. How do things look from your close friend's perspective? Take a few moments to do this. As you continue to watch the situation unfold through your close friend's point of view, try to understand the feelings they have about your situation. What were the underlying causes and reasons?

The self-perspective and observer perspective instructions are adapted from Ayduk and Kross (2008), while the close other perspective is original.

State mood. In order to assess moods that participants were feeling after recalling a conflict event, affective words were selected from the Positive and Negative Affect Scale (PANAS; Watson, Clark, and Tellegen, 1988) and Affect Valuation Index (Tsai, Knutson, and Fung, 2006) to capture most of the affective circumplex, with some emphasis on high arousal negative words. Participants indicated on a 5-point scale $(1=$ not at all, $5=$ extremely $)$ the extent they felt "right now" for high arousal positive emotions (elated, enthusiastic, excited), positive emotions (cheerful, satisfied, happy), and low arousal positive emotions (calm, peaceful, relaxed). These high arousal positive, positive, and low arousal positive emotion words were averaged to create a positive affect (PA) index (European American $\alpha=.91$, Indian $\alpha=.86$ ). Participants also responded to high arousal negative emotions (hostile, fearful, angry, irritated, annoyed, nervous), negative emotions (sad, unhappy, lonely), and low arousal negative emotions (dull, sleepy, sluggish). Because the essay prompt involved a conflict situation, a high arousal negative index (HAN; European American $\alpha=.87$, Indian $\alpha=.86$ ) was created in addition to a negative affect 
(NA) index composed of high arousal negative, negative, and low arousal negative emotions (European American $\alpha=.87$, Indian $\alpha=.92$ ).

Type of perspective-taking. Participants then indicated the extent to which they saw the event from their own perspective (self): "To what extent were you an immersed participant in the situation?"; from an observer perspective: “To what extent were you a distanced participant in the situation?"; from the perspective of a close other: "To what extent did you see the situation from a close friend's point of view?" (1 = not at all, $7=$ completely). The items for assessing the self-perspective and observer perspective are adapted from existing items from Ayduk and Kross (2010), while the close other perspective items is original. Previous research indicates that participants are able to provide accurate self-ratings of the content of their thoughts (see Kross et al., 2012) and that these self-ratings are no different from independent coder ratings.

Thought content. Because previous research has documented a relationship between self-perspective and recounting, and observer perspective and reconstruing, participants answered closed ended questions $(1=$ strongly disagree, $7=$ strongly agree $)$ to evaluate their thought content (items from Ayduk \& Kross, 2010). Recounting consists of two components: (a) "what" aspect: "My thoughts focused on the specific chain of events-sequence of events, what happened, what was said and done — as I thought about the incident", "As I thought about the event I described, I replayed every detail of the event in my mind" and (b) blame: "As I thought about the event I described, I saw the other person being primarily at fault", "As I thought about the event I described, I blamed the other person". An overall recounting index was calculated with all 4 items (European American $\alpha=.64$, Indian $\alpha=.62$ ). Reconstruing also consists of two components: (a) insight: "As I thought about my experience during the study I had a realization that caused me to think differently about the experience", "Thinking about my experience during 
the experiment led me to have a clearer and more coherent understanding of this experience" and (b) closure: "As I thought about my experience during the study I had a realization that made me experience a sense of closure", "I feel a sense of closure about this event”. An overall reconstruing index was calculated with all 4 items (European American $\alpha=.77$, Indian $\alpha=.77$ ).

Psychological distance. To assess psychological distance, participants reported their subjective sense of social distance using the following two items (items from Ross \& Wilson, 2002): "The incident I wrote about: (1=feels like yesterday, $10=$ feels very far away), (1 = feels very close, $10=$ feels very distant). A psychological distance index was computed (European American $\alpha=.89$, Indian $\alpha=.52$ ).

Emotional reactivity. To assess how emotionally aroused participants were after recalling a conflict event, participants rated their agreement to their following items $(1=$ strongly disagree, 7 = strongly agree, items from Ayduk \& Kross, 2010): "I re-experienced the emotions I originally felt during the incident when I think about it now", "As I think about the event now, my feelings and physical reactions to the conflict are still intense", "Thinking about this event still makes me feel angry", "Thinking about this event still makes me feel annoyed", “Thinking about this event still makes me feel irritated". These 5 items were used to compute an emotional reactivity index (European American $\alpha=.93$, Indian $\alpha=.85$ ).

Event saliency. To answer the question of whether participants from different cultural contexts think of similar conflict events, participants answered questions regarding the salience of the event they recalled, including how long ago the event occurred $(1=$ less than 1 month ago, $5=$ more than 4 years ago $)$, whether the event recalled has been resolved $(1=$ unresolved, $7=$ resolved $)$, how vivid and clear the memory was $(1=$ strongly agree, $7=$ strongly disagree $)$, and how emotionally close participants are with the person involved in the event $(1=$ strongly agree, 
7 = strongly disagree $)$. There were no cultural differences in how long ago the event occurred $(M$ $=2.74, S D=1.34)$, whether the event had been resolved $(M=5.13, S D=2.06)$, or the vividness and clarity of the event $(M=5.78, S D=1.27), p s>.49$. Indian participants $(M=6.00, S D=1.17)$ reported being marginally more emotionally close with the person in the event than European American participants $(M=5.72, S D=1.88), t(397)=1.81, p=.07, d=0.18$.

\section{Results}

\section{Overview of Analyses}

Data from the spontaneous condition was used to answer the question concerning the nature of spontaneous perspective-taking in European Americans and Indians, while data from the self-perspective, observer perspective, and close other perspective conditions was used to answer the relative efficacy of observer vs. close other perspective in reducing emotional distress.

\section{Cultural Differences in Spontaneous Perspective-Taking}

Stream of thought essay word count. Because short essay length may be indicative of participants' failure to follow study instructions or participants' lack of motivation to complete

the study, stream of thought essays were screened for total number of words written. The mean number of words written was 83.14 , with a standard deviation of 50.76. Participants who wrote less than 1 standard deviation below the mean ( 32 words) were excluded from the preliminary analyses. However, eliminating short essay length participants did not alter the results. The following analyses include all participants who were assigned to the spontaneous condition.

Mean differences and correlations. Descriptive statistics and summary of cultural group differences can be found in Table 1, and zero-order correlations in Table 2. First, I examined the relationships between culture and type of perspective-taking strategy used. As expected, Indian participants were more likely to report having used observer perspective, $t(91)$ 
$=3.46, p<.01, d=0.72$, and close other perspective, $t(91)=4.52, p<.05, d=0.45$, when analyzing their feelings. Contrary to expectation, European Americans did not report having engaged in more self-perspective compared to Indians $(p=.59)$. To understand the endorsement of each of the perspectives within each cultural context, a series of paired sample t-tests were conducted. Among European Americans, participants reported having engaged in more selfperspective than observer perspective, $t(46)=12.02, p<.001, d=1.75$, more self-perspective than close other perspective, $t(46)=6.75, p<.001, d=0.98$, and more close other-perspective than observer perspective, $t(46)=5.17, p<.001, d=0.75$. The pattern of results were the same for Indian participants, where Indian participants reported having engaged in more selfperspective than observer perspective, $t(44)=6.87, p<.001, d=1.02$, more self-perspective than close other perspective, $t(44)=3.98, p<.001, d=0.59$, and more close other-perspective than observer perspective, $t(45)=2.86, p<.01, d=0.42$.

Second, I examined the relationships between culture and affective outcomes. Indians reported feeling more PA after analyzing their feelings, $t(91)=4.52, p<.001, d=0.94$, but surprisingly no group differences emerged for NA, HAN or emotional reactivity $(p s>.15)$. These findings indicate that after thinking about a conflict event, participants in both cultural groups did not report feeling different for negative emotions, but Indian participants reported feeling better than European Americans, suggesting that Indians analyzed the conflict event in a way that resulted in them feeling more positive.

Third, I examined whether culture was significantly associated with participants' tendencies to engage in particular types of thought. Following Kross et al., (2005), a difference score was computed by subtracting reconstruing thought from recounting thought to create a thought content index where higher scores indicates more emphasis placed on recounting thought 
than reconstruing thought. The thought content index revealed a significant cultural difference where European Americans reported having more recounting thoughts relative to reconstruing thoughts while Indians reported having more reconstruing thoughts relative to recounting thoughts, $t(91)=5.83, p<.001, d=1.21$. Finally, psychological distance, $1^{\text {st }}$ person singular pronoun usage, and $3^{\text {rd }}$ person singular pronoun usage did not differ across cultural groups $(p s>.30)$

Multiple regression. Next, I ran multiple regression analyses to examine the unique variance explained by culture and types of perspective for affective outcomes, thought content, psychological distance, $1^{\text {st }}$ person singular pronoun usage, and $3^{\text {rd }}$ person singular pronoun usage (see Table 3). Culture and close other perspective was associated with more PA, whereas selfperspective and observer perspective were not. Surprisingly, observer perspective was associated with more NA, whereas culture, self-perspective, and close other perspective were not. Also surprisingly, observer perspective was associated with more HAN, although culture, selfperspective, and close other perspective were not. Culture was negatively associated with the thought content index (recount - reconstrue), but self-perspective, observer perspective, and close other perspectives were not. Interestingly, observer perspective was associated with more psychological distance, but close other perspective was associated with less psychological distance, and culture and self-perspective were not associated with psychological distance. Also surprisingly, observer perspective was associated with less use of $3^{\text {rd }}$ person singular pronouns. None of the 4 predictors emerged as significant for emotional reactivity, recounting, or $1^{\text {st }}$ person singular pronouns.

Mediation. Given the significant relationships between culture, close other perspective, and PA; and culture, observer perspective, and thought content, I examined whether the type of 
perspective taken mediates the relationship between culture and emotional/thought content outcomes, as well as whether thought content mediates the relationship between culture and emotional outcomes. Following Shrout and Bolger's (2002) and Hayes (2013) approach for assessing mediation, I first examined the link between the predictor variable culture $(1=$ Indian, $0=$ European American) and the mediator (observer perspective, close other perspective, thought content) (effect $a$ ). Next, I examined the link between the mediator and outcome variable (PA or thought content), while controlling for the direct effect of the predictor variable on the outcome variable (effect $b$ ). Using a 5000 sample bias-corrected bootstrap method (analytic framework PROCESS; Hayes, 2013), I then examined the indirect path from the predictor variable through the mediator to the outcome variable (indirect effect, $a b$ ). Finally, I examined the link between the predictor variable culture and the outcome variable, while controlling for the link between the mediator and outcome variable (direct effect, $c^{\prime}$ ). See Table 4 for a summary of the unstandardized coefficients (advocated by Hayes, 2013) in the mediation analysis.

Does close other perspective mediate the link between culture and PA? Close other perspective does indeed mediate the link between culture and PA as evidenced by the $95 \%$ confidence interval (CI) for the indirect effect, $a b[.01, .27]$ being above zero. ${ }^{3}$ Preacher and Kelley's Kappa Squared (2011) indicates that the indirect effect size is 0.06 [.01, .14], meaning that the observed indirect effect is about $6 \%$ as large as its maximum possible value given the associations between the variables in the analysis. The mediation analysis reveals that Indians reported feeling more PA in part because they spontaneously used the close other perspective more than European Americans, suggesting that the close other perspective helps Indian

\footnotetext{
${ }^{3}$ Hayes (2013) advocates against using the Sobel test where possible due to low power and unreliable normality assumption, especially for small sample sizes. Sobel's $Z=1.54, p=.12$.
} 
participants analyze the conflict event in a way that made them feel more positive. See Figure 1 for path analysis diagram.

Does observer perspective mediate the link between culture and thought content?

Observer perspective does not mediate the link between culture and thought content, as the $95 \%$ CI for the indirect effect, $a b[-.37, .05]$ contains zero. ${ }^{4}$

Does thought content mediate the link between culture and PA? Thought content does indeed mediate the link between culture and PA as evidenced by the $95 \%$ confidence interval (CI) for the indirect effect, $a b[.01, .49]$ being above zero. ${ }^{5}$ Preacher and Kelley's Kappa Squared (2011) indicates that the indirect effect size is $0.12[.01, .23]$, meaning that the observed indirect effect is about $12 \%$ as large as its maximum possible value given the associations between the variables in the analysis. The mediation analysis reveals that Indians reported feeling more PA in part because they had relatively more reconstruing thoughts than recounting thoughts compared to European Americans, suggesting that having relatively more reconstruing thoughts helps Indian participants analyze the conflict event in a way that made them feel more positive. See Figure 2 for path analysis diagram.

\section{Summary of Findings for Cultural Differences in Spontaneous Perspective-Taking}

Indian participants were significantly more likely than European Americans to report having used the observer perspective and close other perspective when analyzing feelings about a conflict event, and both cultural groups reported using the close other perspective more than the observer perspective. Interestingly, no cultural differences emerged for the use of selfperspective. Of the affective outcome measures, only one cultural difference emerged: Indians reported feeling significantly more positive than European Americans after analyzing their

\footnotetext{
${ }^{4}$ Sobel's $Z=-.98, p=.33$.

${ }^{5}$ Sobel's $Z=2.00, p<.05$.
} 
feelings towards a conflict event. No cultural differences emerged for NA, HAN, or emotional reactivity. The computation of the thought content index (recount - reconstrue) revealed that Indians reported having engaged in significantly more reconstrual and less recounting than European Americans. Finally, no cultural differences emerged for psychological distance, proportional use of $1^{\text {st }}$ person singular pronouns, or $3^{\text {rd }}$ person singular pronouns.

Zero-order correlations and multiple regression analyses revealed significant relationships between culture and PA, culture and close other perspective, close other perspective and PA, culture and thought content, and thought content and PA. Close other perspective does mediate the relationship between culture and PA, indicating that Indians reported feeling more PA in part because they spontaneously used the close other perspective more than European Americans. This suggests that the close other perspective helps Indian participants analyze the conflict event in a way that made them feel more positive. Furthermore, thought content does mediate the relationship between culture and PA, indicating that Indians reported feeling more PA in part because they had relatively more reconstruing thoughts than recounting thoughts compared to European Americans. Taken together, these two mediation findings suggest that the tandem effect of employing a close other perspective and having more reconstruing thoughts (relative to recounting thoughts) help Indian participants analyze the conflict event in a way that made them feel more positive.

\section{Experimentally Manipulated Perspectives}

Stream of thought essay word count. Because short essay length may be indicative of participants' failure to follow study instructions or participants' lack of motivation to complete study, stream of thought essays were screened for total number of words written. The mean number of words written was 71.19, with a standard deviation of 51.3. Participants who wrote 
less than $1 S D$ below the mean (20 words) were excluded from the preliminary analyses. However, eliminating short essay length participants did not alter the results. The following analyses include all participants who were assigned to the experimental conditions.

Manipulation check. To assess whether the experimental manipulation effectively elicited self-perspective, and outsider perspectives (observer perspective, close other perspective), $2 \times 3$ (Culture X Condition) ANOVAs were conducted on the proportional use of $1^{\text {st }}$ person singular pronouns and $3^{\text {rd }}$ person singular pronouns in the stream of thought essays, and on each of the items that assess the type of perspective taken when participants were analyzing their feelings (“immersed participant”, “distanced participant”, “close friend's point of view”).

$\boldsymbol{I}^{\text {st }}$ person singular pronouns. There was an effect of Culture, $F(1,301)=6.04, p<.05$, $\eta^{2}=.02$, where Indian participants $(M=9.98 \%, S D=5.38 \%)$ used proportionally more $1^{\text {st }}$ person singular pronouns in their stream of thought essays than European Americans $(M=$ $8.43 \%, S D=5.01 \%)$. There was also an effect of Condition, $F(2,301)=3.86, p<.05, \eta^{2}=.02$, where follow up Tukey analyses revealed that participants in the Self-Perspective Condition used proportionally more $1^{\text {st }}$ person singular pronouns than participants in the Observer Perspective Condition and Close Other Perspective Condition $\left(M_{\text {differences }}=1.71 \%\right.$ and $\left.1.85 \%, p \mathrm{~s}<.05\right)$. There was no Culture $\mathrm{X}$ Condition interaction, $p=.32$ (see Figure 3).

$3^{\text {rd }}$ person singular pronouns. There was no effect of Culture, $p=.31$. There was an effect of Condition, $F(2,301)=4.78, p<.01, \eta^{2}=.03$, where follow up Tukey analyses revealed that participants in the Observer Perspective Condition used proportionally more $3^{\text {rd }}$ person singular pronouns than participants in the Self-Perspective Condition and Close Other Perspective Condition $\left(M_{\text {differences }}=1.66\right.$ and $\left.1.77, p s<.05\right)$. There was also a marginally significant Culture X Condition interaction, $F(2,301)=2.32, p=.10, \eta^{2}=.01$ (see Figure 4), 
where follow-up Tukey analyses revealed that the condition differences were driven by the European American participants, $F(2,151)=5.60, p<.01, \eta^{2}=.07$, such that participants in the Observer Perspective Condition used proportionally more $3^{\text {rd }}$ person singular pronouns than participants in the Close Other Perspective Condition $\left(M_{\text {difference }}=3.06 \%, p<.01\right)$, and marginally more $3^{\text {rd }}$ person singular pronouns than participants in the Self-Perspective Condition $\left(M_{\text {difference }}=2.04 \%, p=.09\right)$.

Self-perspective. Surprisingly, there was no effect of Culture or Condition ( $p s>.63)$ on the self-perspective item. There was a marginally significant effect of Culture X Condition, $F(2$, $301)=2.46, p=.09, \eta^{2}=.02$ (see Figure 5), suggesting that despite the different study instructions across conditions, all participants used the self-perspective as one of their strategies when analyzing their feelings (grand $M=5.62, S D=1.37$ ).

Observer perspective. There was an effect of Culture, $F(1,298)=12.89, p<.001, \eta^{2}$ $=.04$, where Indian participants reported using the observer perspective more than European Americans. As expected, there was an effect of Condition, $F(2,298)=9.98, p<.001, \eta^{2}=.06$, on the observer perspective item. A post-hoc Tukey test revealed that endorsement of the observer perspective item was statistically higher for participants in the Observer Perspective and Close Other Perspective Conditions than for participants in the Self-Perspective Condition $\left(M_{\text {differences }}=1.12\right.$ and 0.80 respectively, $\left.p s<.05\right)$.

There was also an effect of Culture $X$ Condition, $F(2,298)=3.97, p<.05, \eta^{2}=.02$ (see Figure 6) on the observer perspective item, indicating that participants from the two cultural groups endorsed the observer perspective item differently. Follow-up Tukey analyses revealed that the condition differences were driven by the European American participants, $F(2,149)=$ $12.45, p<.001, \eta^{2}=.14$, such that endorsement of the observer perspective item was statistically 
higher for European American participants in the Observer Perspective and Close Other Perspective Conditions than for European American participants in the Self-Perspective Condition $\left(M_{\text {differences }}=1.88\right.$ and 1.56 respectively, $\left.p s<.001\right)$.

Close other perspective. There was an effect of Culture, $F(1,301)=22.34, p<.001, \eta^{2}$ $=.05$, where Indian participants reported using the close other perspective more than European Americans. As expected, there was an effect of Condition, $F(2,301)=42.84, p<.001, \eta^{2}=.21$ on the close other perspective item. A post-hoc Tukey test revealed that endorsement of the close other perspective item was statistically higher for participants in the Close Other Perspective Condition than for participants in the Self-Perspective Condition and the Observer Perspective Condition $\left(M_{\text {differences }}=2.05\right.$ and 1.76 respectively, $\left.p s<.001\right)$.

There was also an effect of Culture X Condition, $F(2,301)=9.30, p<.001, \eta^{2}=.04$ (see Figure 7), on the close other perspective item, indicating that participants from the two cultural groups endorsed the close other perspective item differently. Follow up Tukey analyses revealed that the condition differences for the European American participants, $F(2,151)=45.36, p$ $<.001, \eta^{2}=.38$, were such that endorsement of the close other perspective item was statistically higher for participants in the Close Other Perspective Condition than for participants in the SelfPerspective Condition and the Observer Perspective Condition $\left(M_{\text {differences }}=3.15\right.$ and 2.19 respectively, $p s<.001)$. Furthermore, endorsement of the close other perspective item was statistically higher for participants in the Observer Perspective Condition than for participants in the Self-Perspective Condition $\left(M_{\text {difference }}=0.97, p<.05\right)$. The condition differences for the Indian participants, $F(2,150)=8.51, p<.001, \eta^{2}=.10$, were such that endorsement of the close other perspective item was statistically higher for participants in the Close Other Perspective 
Condition than for participants in the Self-Perspective Condition and the Observer Perspective Condition $\left(M_{\text {differences }}=1.10\right.$ and 1.32 respectively, $\left.p \mathrm{~s}<.01\right)$.

PA, NA, HAN, and emotional reactivity. To assess whether the manipulation produced differences in participants' affective state, a 2 X 3 (Culture X Condition) ANOVA was conducted on each of the dependent affective variables: PA, NA, HAN, and emotional reactivity.

$\boldsymbol{P A}$. Surprisingly, there was no effect of Condition on PA, $p=.94$. However, there was a significant effect of Culture, $F(1,301)=76.93, p<.001, \eta^{2}=.20$, where Indian participants reported feeling more PA than European Americans after analyzing their feelings towards the conflict event (see Figure 8). There was also no Culture X Condition interaction. $p=.16$.

NA. Surprisingly, there was no effect of Condition on NA, $p=.53$. However, there was a significant effect of Culture, $F(1,301)=34.28, p<.001, \eta^{2}=.10$, where Indian participants reported feeling more NA than European Americans after analyzing their feelings towards the conflict event. Furthermore, there was also a significant Culture X Condition interaction, $F(2$, $301)=3.44, p<.05, \eta^{2}=.02$ (see Figure 9). Follow up Turkey analyses revealed that the interaction was being marginally driven by the Indian participants. There was an effect of Condition on NA, $F(2,150)=2.75, p=.07, \eta^{2}=.04$, such that participants in Observer Perspective Condition reported feeling marginally more NA than participants in the SelfPerspective Condition $\left(M_{\text {difference }}=0.40, p=.06\right)$.

$\boldsymbol{H A N}$. Surprisingly, there was no effect of Condition on HAN, $p=.73$. However, there was a significant effect of Culture, $F(1,301)=36.01, p<.001, \eta^{2}=.10$, where Indian participants reported feeling more HAN than European Americans after analyzing their feelings towards the conflict event. Furthermore, there was also a significant Culture $\mathrm{X}$ Condition interaction, $F(2,301)=3.50, p<.05, \eta^{2}=.02$ (see Figure 10). Follow up Tukey analyses 
revealed that the interaction was being marginally driven by the Indian participants. There was an effect of Condition on $\operatorname{HAN} F(2,150)=2.49, p=.09, \eta^{2}=.03$, such that participants in Observer Perspective Condition reported feeling marginally more HAN than participants in the Self-Perspective Condition $\left(M_{\text {difference }}=0.39, p=.09\right)$.

Emotional reactivity. Surprisingly, there was no effect of Condition on emotional reactivity, $p=.70$. However, there was a significant effect of Culture, $F(1,301)=15.85, p<.001$, $\eta^{2}=.05$, where Indian participants reported being more emotionally reactive than European Americans after analyzing their feelings towards the conflict event (see Figure 11). Furthermore, there was no significant Culture X Condition interaction $(p=.12)$ as follow up Tukey analyses did not reveal a significant effect of Condition for European Americans or Indians.

Recounting and reconstruing (thought content). Following Kross et al., (2005), a difference score was computed by subtracting reconstruing thought from recounting thought to create a thought content index where higher scores indicates more emphasis placed on recounting thought than reconstruing thought. To assess whether the manipulation produced differences in participants' thought content a 2 X 3 (Culture X Condition) ANOVA was conducted.

There was an effect of Culture, $F(1,301)=65.22, p<.001, \eta^{2}=.16$, where European American participants reported having relatively more recounting thoughts than reconstruing thoughts than Indians. There was also an effect of Condition, $F(2,301)=7.25, p<.01, \eta^{2}=.04$. Follow up Tukey analyses revealed that participants in the Self-Perspective Condition reported having relatively more recounting thoughts than participants in the Observer Perspective Condition $\left(M_{\text {difference }}=0.67, p<.01\right)$, and marginally more recounting thoughts than participants in the Close Other Perspective Condition $\left(M_{\text {difference }}=0.43, p=.11\right)$. There was also a Culture X 
Condition interaction, $F(2,301)=10.11, p<.001, \eta^{2}=.05$ (see Figure 12). Follow up Tukey analyses revealed that this interaction was driven by European American participants, $F(2,151)$ $=10.10, p<.001, \eta^{2}=.12$, where participants in the Self-Perspective Condition reported having relatively more recounting thoughts than participants in the Observer Perspective Condition and Close Other Perspective Condition $\left(M_{\text {differences }}=1.60\right.$ and 1.35 respectively, $\left.p<.01\right)$.

Psychological distance. There were no effects of Culture, Condition, or Culture X Condition $(p s>.46)$.

Mediation. Next, I examined whether thought content mediates the relationship between culture and emotional outcomes (PA, NA, HAN, and emotional reactivity). Following Shrout and Bolger's (2002) and Hayes (2013) approach for assessing mediation that I described earlier, I used culture as the predictor variable because the earlier manipulation check analyses revealed Culture X Condition interactions, indicating that participants followed the experimental manipulations by also imbuing it with their cultural worldview. See Table 5 for a summary of the unstandardized coefficients in the mediation analysis.

Does thought content mediate the relationship between culture and PA? The 95\% confidence interval (CI) for the indirect effect, $a b[.05, .23]$ is completely above zero. ${ }^{6}$ Preacher and Kelley’s Kappa Squared (2011) indicates that the indirect effect size is 0.07 [.03, .12], meaning that the observed indirect effect is about $7 \%$ as large as its maximum possible value given the associations between the variables in the analysis. The mediation analysis reveals that Indians reported feeling more PA in part because they engaged in relatively more reconstruing thought than recounting thought when analyzing their feelings compared to European

\footnotetext{
${ }^{6}$ As mentioned previously, Hayes (2013) advocates using 95\% CI as opposed to Sobel test for establishing significance. Sobel's $Z=2.90, p<.01$.
} 
Americans. ${ }^{7}$ This suggests that engaging in reconstruing thought helps Indian participants feel better after analyzing a conflict event. See Figure 13 for path analysis diagram.

Does thought content mediate the relationship between culture and NA? The 95\% confidence interval $(\mathrm{CI})$ for the indirect effect, $a b[-.20,-.04]$ is completely below zero. ${ }^{8}$ However, the indirect effect, $a b$ has the opposite sign of the direct effect, $c^{\prime}[.46, .86]$ indicating that thought content does not explain the cultural differences in NA.

Does thought content mediate the relationship between culture and HAN? The 95\% confidence interval $(\mathrm{CI})$ for the indirect effect, $a b[-.25,-.07]$ is completely below zero. ${ }^{9}$ However, the indirect effect, $a b$ has the opposite sign of the direct effect, $c^{\prime}[.56, .99]$ indicating that thought content does not explain the cultural differences in HAN.

\section{Does thought content mediate the relationship between culture and emotional}

reactivity? The $95 \%$ confidence interval $(\mathrm{CI})$ for the indirect effect, $a b[-.78,-.40]$ is completely below zero. ${ }^{10}$ However, the indirect effect, $a b$ has the opposite sign of the direct effect, $c$ ' [.93, 1.57] indicating that thought content does not explain the cultural differences in emotional reactivity.

\section{Summary of Findings for Experimentally Manipulated Perspectives}

A manipulation check based on the proportion of $1^{\text {st }}$ person singular pronouns used revealed that Indian participants were significantly more likely to include pronouns such as I, me,

\footnotetext{
${ }^{7}$ It is also possible that PA mediates the link between culture and thought content. Indeed, the indirect effect, $a b$ is significant, $-.28(.10)[-.50,-.11]$, Sobel's $Z=-2.96, p<.01$. Preacher and Kelley's Kappa Squared $=.08[.03, .14]$. The temporal sequence of events in the experiment suggests it is more appropriate to consider thought content as the mediator. Participants were first asked to analyze their feelings towards a conflict event, before reporting how they "feel right now".

8 Sobel's $Z=-2.54, p<.05$.

${ }^{9}$ Sobel's $Z=-3.13, p<.01$.

${ }^{10}$ Sobel's $Z=-5.74, p<.001$.
} 
my in their stream of thought essays when analyzing their feelings towards a conflict event. Furthermore, participants in the Self-Perspective Condition were significantly more likely to use $1^{\text {st }}$ person singular pronouns than participants in the Observer Perspective Condition or Close Other Perspective Condition. This is in contrast with the self-perspective item that showed participants across both cultures and all conditions endorsed the item equally.

A manipulation check based on the proportion of $3^{\text {rd }}$ person singular pronouns used revealed that participants in the Observer Perspective Condition were significantly more likely to use pronouns such as she, he than participants in the Self-Perspective Condition and Close Other Condition. A manipulation check on the observer perspective item revealed that Indians reported using the observer perspective more than European Americans. Furthermore, participants in the Observer Perspective Condition were more likely to endorse using the observer perspective than Self-Perspective Condition and Close Other Perspective Condition participants. However, this was also qualified by a Culture X Condition interaction, where significant condition differences emerged for European American participants. Among the European American participants, they were significantly more likely to endorse the observer perspective item in the Observer Perspective and Close Other Perspective Conditions compared to the Self-Perspective Condition.

A manipulation check on the close other perspective item also revealed that Indian participants reported using the close other perspective more than European Americans. Participants in the Close Other Perspective Condition were more likely to endorse the close other perspective item than participants in the Self-Perspective Condition and Observer Perspective Condition. However, these differences were qualified by a Culture X Condition interaction, where European Americans in the Close Other Perspective Condition were most likely to endorse the close other perspective item, followed by participants in the Observer Perspective 
Condition, and lastly by the participants in the Self-Perspective Condition. For the Indian participants, the endorsement of the close other perspective item was the highest for participants in the Close Other Perspective Condition, but there were no differences between the SelfPerspective Condition and Observer Perspective Condition. These manipulation check findings for outsider perspectives indicate that participants did indeed follow the study instructions.

An analysis of the affective outcomes revealed that Indian participants were more likely to report feeling more PA than European Americans after analyzing a conflict event. For NA and HAN, Indians were also more likely to report feeling these emotions than European Americans, but the effect was qualified by a Culture X Condition interaction such that Indian participants report feeling these emotions the most in the Observer Perspective Condition compared to the Self-Perspective Condition. For emotional reactivity, Indians were also more likely to report feeling intense emotions after analyzing a conflict event compared to European Americans.

The computation of the thought content index (recount - reconstrue) revealed that European Americans were more likely to report having engaged in relatively more recounting thoughts than reconstruing thoughts compared to Indians. Furthermore, participants in the SelfPerspective Condition were more likely to report having engaged in relatively more recounting thoughts than reconstruing thoughts compared to participants in the Observer Perspective Condition. These effects were qualified by a Culture X Condition interaction driven by the European Americans where participants in the Self-Perspective Condition reported having relatively more recounting thoughts than participants in the Observer Perspective and Close Other Perspective Conditions. 
Psychological distance was measured as an alternative to thought content as a mediating mechanism. However, there were no effects of Culture, Condition, or Culture X Condition interaction.

In an effort to replicate previous findings where thought content explained the link between culture and emotional outcomes, a mediation analysis with culture as the predictor and thought content as the mediator was conducted on each of the emotional outcome variables, PA, NA, HAN, and emotional reactivity. Thought content was indeed a significant mediator for the link between culture and PA, but not for NA, HAN, or emotional reactivity. The mediational analysis suggests that engaging in relatively more reconstruing thought than recounting thought helps Indians feel better after analyzing a conflict event compared to European Americans.

\section{Discussion}

The main goals of the present investigation were (1) understand the phenomenology of how different types of perspective-taking are used in different cultural contexts, and (2) compare the efficacy of the newly proposed close other perspective with that of the already studied observer perspective. First, I sought to compare the perspective-taking strategies spontaneously used by European Americans and Indians because most of the existing findings have been based on American samples (that promote an independent model of self), and few studies to date have examined perspective-taking strategies in cultures that promote an interdependent model of self

(e.g., Indians). Second, I proposed studying a third type of perspective in addition to the existing perspectives, that of close other perspective, because it may be more efficacious in generating reconstrual thoughts and reducing emotional distress than the observer perspective. 


\section{Spontaneous Perspective-Taking}

The findings from the first part of the study on spontaneous perspective-taking replicated previous findings that European Americans are less likely to use the observer perspective, and that this is associated with relatively more thoughts of recounting and fewer thoughts of reconstrual (e.g., Kross et al., 2005). Interestingly, although previous research also associated the lack of observer perspective with greater emotional distress (more NA, HAN, and emotional reactivity), there was no evidence of this for European Americans. The participants however, did report feeling less PA, and a mediational analysis revealed that this was indirectly explained by the tendency for European Americans to engage in relatively more recounting than reconstruing thought.

Indian participants on the other hand, reported using the observer perspective more, and having engaged in more thoughts of reconstrual relative to recounting. Furthermore, Indian participants reported feeling more PA after analyzing their feelings towards a conflict event (but no differences in NA, HAN, or emotional reactivity). A mediation analysis revealed that feeling more PA was indirectly explained by Indians' tendency to engage in relatively more reconstruing than recounting thought. These new cultural findings from Indian participants also concur with the existing findings from Russian participants (Grossmann \& Kross, 2010), where Russians are more likely to spontaneously adopt an observer perspective and report engaging in relatively more reconstruing thoughts than recounting thoughts. The agreement between Indians are Russians are reassuring, because Russians, like Asians/Indians, score higher on measures of collectivism and interdependence than Western Europeans and North Americans (Matsumoto, Takeuchi, Andayani, Kouznetsova, \& Krupp, 1998; Naumov \& Puffer, 2000; Realo \& Allik, 1999; Tower, Kelly, \& Richards, 1997). 
In contrast with previous research, European Americans and Indians did not differ in how much they used the self-perspective when analyzing their feelings about a conflict event. It is possible that perhaps all participants use a fair degree of self-perspective when analyzing a conflict event, and that it is more important to consider the relative use of the self-perspective compared to the observer perspective. Indeed, some previous studies have measured the selfperspective and observer perspective using one bipolar item (e.g., Ayduk \& Kross, 2010). It was not possible to measure the types of perspectives used in the current study using a biopolar item as I was also interested in a third perspective, that of a close other.

European American and Indian participants both reported having used the close other perspective when analyzing their feelings about a conflict event. Indeed, participants in both cultural contexts reported using the close other perspective more than observer perspective, but less than the self-perspective. In terms of mean differences, Indian participants were more likely than European Americans to use the close other perspective. The close other perspective also mediated the relationship between culture and PA, indicating that Indians reported feeling more PA in part because they spontaneously adopted the close other perspective more than European Americans. This finding, along with the earlier mediation finding where thought content explained the link between culture and PA, suggest that it is the tandem effect of employing a close other perspective and having relatively more reconstruing thoughts than recounting thoughts that help Indian participants analyze a conflict event in a way that made them feel more positive. These findings on close other perspective are novel and add to the existing literature on how culture influences the types of perspective-taking naturally taken. 


\section{Experimentally Manipulated Perspectives}

Because the patterns of results are different for European Americans and Indians, I discuss the findings by cultural group separately.

European Americans. Experimentally manipulating the type of perspective taken among European American participants replicated previous findings where participants assigned to the Self-Perspective Condition were more likely to have relatively more thoughts of recounting and fewer thoughts of reconstrual, and experience greater emotional distress compared to participants assigned to the Observer Condition (e.g., Kross et al., 2005) .Although there was no significant effect of Condition on NA, HAN, or emotional reactivity for the European Americans, the means were in the predicted direction. European American participants in the Self-Perspective Condition reported feeling greater NA, HAN, and emotional reactivity than participants in the Observer Condition. Although also not significant, European American participants in the SelfPerspective Condition trended towards feeling less PA than participants in the Observer Perspective Condition. The thought content results are more conclusive in its support for previous findings. European American participants in the Self-Perspective Condition reported having significantly more recounting thoughts than reconstruing thoughts than participants in the Observer Perspective Condition.

The inclusion of a third type of perspective, that of the close other perspective revealed more similarities with the observer perspective than differences. As mentioned previously, among European Americans, there were no significant effects of Condition for any of the emotional outcome variables, but the means for the Close Other Perspective Condition are more similar to the means for the Observer Perspective Condition than for the Self-Perspective Condition. Findings for thought content revealed no significant differences between the Close 
Other Perspective Condition and the Observer Perspective Condition (but these are significantly different from the Self-Perspective Condition). Although it was expected that the close other perspective would be more efficacious that the observer perspective in reducing emotional distress and generating reconstrual, the greatest differences appear to be between the SelfPerspective Condition and the Observer Perspective Condition.

Indians. Surprisingly, Indian participants who were assigned to the Observer Perspective Condition trended towards feeling more NA, HAN, and emotional reactivity compared to participants assigned to the Self-Perspective Condition. There was also a trend for participants in the Observer Perspective Condition to feel less PA than participants in the Self-Perspective Condition. Consistent with these surprising findings, Indian participants in the Self-Perspective Condition trended towards engaging in more reconstruing thought than recounting thought, compared to participants in the Observer Condition. Like the European American participants, the Indian participants did not discriminate much between the Close Other Perspective Condition and the Observer Perspective Condition. The greatest differences between conditions appeared to be between the Self-Perspective Condition and the Observer Perspective Condition.

One possible reason for these seemingly anomalous Indian findings may be due to cultural differences in emotional experience. Kitayama, Mesquita, and Karasawa (2006) found that individuals from cultures that promote an independent model of self (e.g., Americans) are more likely to experience socially disengaging emotions (e.g., anger, pride), while individuals from cultures that promote an interdependent model of self (e.g., Indians) are more likely to experience socially engaging emotions (e.g., shame, sympathy). Indeed, folk theories in India encourage civilizing emotions (e.g., shame, modesty) and discourage uncivilizing emotions (e.g., anger) (Menon, 2000), and comparisons of Americans and Indians have also observed similar 
findings in participants' spontaneous reports of felt emotion (Crowe, Raval, Trivedi, Daga, \& Raval, 2012). All the measures concerning negative emotion in the current study were focused on socially disengaging emotions (e.g., "how angry do you feel right now?") and did not include any socially engaging emotions (e.g., "how guilty do you feel right now?”). Because socially engaging emotions are more frequent and more encouraged in Indian contexts, the lack of opportunity to express such emotions especially in situations where the focus is directed away from the self (adoption of outsider perspectives: observer perspective and close other perspective) may amplify socially disengaging emotions. Furthermore, perhaps the use of outsider perspectives in Indian participants may be more tightly associated with reducing emotional distress in socially engaging emotions but not socially disengaging emotions. Future studies should explore these possibilities by including socially engaging and disengaging emotions when assessing affect.

One may be asking the question, why did the findings from the Indian participants in the spontaneous condition not show a pattern of results contrary to prediction as in the experimentally manipulated conditions? The key difference between the spontaneous condition and the experimentally manipulated conditions is whether the participant had the latitude to engage in a variety of different perspectives. Based on participants' reports of how much they endorsed the self-perspective, observer perspective, and close other perspective items in the spontaneous condition, it is clear that participants employed a mix of the three different perspectives. However, in the experimentally manipulated conditions, participants were specifically asked to analyze their feelings towards the conflict event in a specific way. The relative lack of ability to consider other types of perspectives may cause Indian participants to 
amplify socially disengaging emotions, but not when participants have the ability to flexibility engage in a variety of perspectives.

Comparing across cultures. Indian participants reported feeling more PA, NA, HAN, and emotional reactivity compared to European Americans after analyzing a conflict event. Indian participants also reported having relatively more reconstrual thoughts than recounting thoughts compared to European Americans. In an attempt to replicate previous findings where thought content explained the link between culture and emotional outcomes, several analyses with culture as the predictor, thought content as the mediator, and PA, NA, HAN, or emotional reactivity as the outcome variable was conducted. Thought content only explained the relationship between culture and PA, suggesting that engaging in relatively more reconstruing thought than recounting thought helps Indians feel better after analyzing a conflict event compared to European Americans.

\section{Future Directions}

It is clear that the current study only represents a first step in understanding the phenomenology of how Indians and European Americans self-reflect about a conflict event. Although adopting outsider perspectives was not shown to be beneficial across the board, it was at least beneficial for those in the spontaneous condition and for European Americans in the experimentally manipulated conditions. It remains to be seen however, whether the use of outsider perspectives is also effective for other types of negative events (e.g., sadness, rejection) across different cultural contexts. To date, the only studies that have included participants other than Americans (the current study and Grossmann and Kross, 2010) have only examined conflict events. Furthermore, it remains to be tested whether the strategies recommended here work for people who have extreme conflict episodes, such as individuals who have severe problems with 
anger management. Previous work on analyzing reasons for a sad event has found that adopting an observer perspective is effective even for individuals with Major Depressive Disorder (Kross et al., 2012).

Finally, is it possible to train individuals who don't already spontaneously use outsider perspectives to do so automatically? Individuals from interdependent cultural contexts spontaneously use outsider perspectives presumably because they are a functional response to the demands of fitting in, adjusting the self to the situation, and not standing out (Heine et al., 1999; Morling et al., 2002). To train individuals from independent contexts who do not have the same social landscape as interdependent individuals may be difficult, but the benefits of automatically adopting outsider perspectives may improve psychological well-being.

\section{Conclusions}

The findings of the present investigation provide a more complete picture of the phenomenology of how Indians and European Americans self-reflect about a conflict event. When individuals are asked to spontaneously self-reflect about a conflict event, Indian participants are more likely to reflect using outsider perspectives (observer perspective or close other perspective) than European Americans. Self-reflecting using outsider perspectives has been shown to increase thoughts of reconstrual (vs. recounting) and increase positive affect. Second, experimental manipulations of observer perspective and close other perspective do not reveal any differences in efficacy for European Americans, therefore implying adoption of either one of the strategies is an ideal approach to generate insight and understanding when self-reflecting on a conflict event. 


\section{References}

Ayduk, O., \& Kross, E. (2008). Enhancing the pace of recovery: Differential effects of analyzing negative experiences from a self-distanced vs. self-immersed perspective on blood pressure reactivity. Psychological Science, 19, 229-231.

Ayduk, O., \& Kross, E. (2010). From a distance: Implications of spontaneous self-distancing for adaptive self-reflection. Journal of Personality and Social Psychology, 98, 809-829.

Batson, C. D., Early, S., \& Salvarani, G. (1997). Perspective taking: Imagining how another feels versus imagining how you would feel. Personality and Social Psychology Bulletin, 23, 751-758.

Batson, C. D., Lishner, D. A., Carpenter, A., Dulin, L., Harjusola-Webb, S., Stocks, E. L., .. .Sampat, B. (2003). “...As you would have them do unto you”: Does imagining yourself in the other's place stimulate moral action? Personality and Social Psychology Bulletin, 29, 1190-1201.

Buhrmester, M., Kwang, T., \& Gosling, S. D. (2011). Amazon's Mechanical Turk: A new source of inexpensive yet high-quality, data? Perspectives on Psychological Science, 6, 3-5.

Cohen, D., \& Gunz, A. (2002). As seen by the other...: Perspectives on the self in the memories and emotional perceptions of Easterners and Westerners. Psychological Science, 13, 5559.

Cohen, D., Hoshino-Browne, E., \& Leung, A. K-y. (2007). Culture and the structure of personal experience: Insider and outsider phenomenologies of the self and social world. In M. P. Zanna (Ed.), Advances in Experimental Social Psychology (pp. 1-67). San Diego: Academic Press. 
Crowe, M., Raval, V. V., Trivedi, S. S., Daga, S. S., \& Raval, P. H. (2012). Processes of emotion communication and control: A comparison of India and the United States. Social Psychology, 43, 205-214.

Davis, M. H. (1983). Measuring individual differences in empathy: Evidence for a multidimensional approach. Journal of Personality and Social Psychology, 44, 113-126.

Davis, M. H., Conklin, L., Smith, A., \& Luce, C. (1996). Effect of perspective taking on the cognitive representation of persons: A merging of self and other. Journal of Personality and Social Psychology, 70, 713-726.

Davis, M. H., Soderlund, T., Cole, J., Gadol. E., Kute, M., Myers, M., \& Weihing, J. (2004). Cognitions associated with attempts to empathize: How do we imagine the perspective of another? Personality and Social Psychology Bulletin, 30, 1625-1635.

Epley, N., \& Caruso, E. M. (2008). Perspective taking: Misstepping into others' shoes. In K. D. Markman, W. M. P. Klein, \& J. A. Suhr (Eds.), The handbook of imagination and mental simulation (pp. 295-309). New York: Psychology Press.

Epley, N., Keysar, B., Van Boven, L., \& Gilovich, T. (2004). Perspective taking as egocentric anchoring and adjustment. Journal of Personality and Social Psychology, 87, 327-339.

Fenigstein, A. (1979). Self-consciousness, self-attention, and social interaction. Journal of Personality and Social Psychology, 37, 75-86.

Galinsky, A. D., Ku, G., \& Wang, C. S. (2005). Perspective-taking and self-other overlap: Fostering social bonds and facilitating social coordination. Group Processes \& Intergroup Relations, 8, 109-124. 
Galinsky, A. D., \& Moskowitz, G. B. (2000). Perspective-taking: Decreasing stereotype expression, stereotype accessibility, and in-group favoritism. Journal of Personality and Social Psychology, 78, 708-724.

Grant, A. M., Franklin, J., \& Langford, P. (2002). The self-reflection and insight scale: A new measure of private self-consciousness. Social Behavior and Personality, 30(8), 821-836.

Grossmann, I. \& Kross, E. (2010). The impact of culture on adaptive vs. maladaptive selfreflection. Psychological Science, 21, 1150-1157.

Harrington, R., \& Loffredo, D. A. (2010). Insight, rumination, and self-reflection as predictors of well-being. Journal of Psychology: Interdisciplinary and Applied, 145, 39-57.

Hayes, A. F. (2003). Introduction to mediation, moderation, and conditional process analysis: A regression based approach. New York: Guilford Press.

Heine, S. J., Lehman, D. R., Markus, H. R., \& Kitayama, S. (1999). Is there a universal need for positive self-regard? Psychological Review, 106, 766-794.

Hodges, S. D., Clark, B., \& Myers, M. W. (2011). Better living through perspective taking. In R. Biswas-Diener (Ed.), Positive psychology as a mechanism for social change (pp. 193218). Dordrecht, The Netherlands: Springer Press.

James, W. (1890). Principles of psychology. Cambridge, MA: Harvard University Press.

Joireman, J. A., Parrott, L., \& Hammersla, J. (2002). Empathy and the self-absorption paradox: Support for the distinction between self-rumination and self-reflection. Self and Identity, $1,53-65$.

Keysar, B., Barr, D. J., Balin, J. A., \& Brauner, J. S. (2000). Taking perspective in conversation: The role of mutual knowledge in comprehension. Psychological Science, 11, 32-38. 
Kitayama, S., Mesquita, B., \& Karasawa, M. (2006). Cultural affordances and emotional experience: Socially engaging and disengaging emotions in Japan and the United States. Journal of Personality and Social Psychology, 91, 890-903.

Kross, E., \& Ayduk, O. (2008). Facilitating adaptive emotional analysis: Short-term and longterm outcomes distinguishing distanced-analysis of negative emotions from immersedanalysis and distraction. Personality and Social Psychology Bulletin, 34, 924-938.

Kross, E., \& Ayduk, O. (2009). Boundary conditions and buffering effects. Does depressive symptomology moderate the effectiveness of self-distancing for facilitating adaptive emotional analysis? Journal of Research in Personality, 43, 923-927.

Kross, E., \& Ayduk, O. (2011). Making meaning out of negative experiences by self-distancing. Current Directions in Psychological Science, 20, 187-191.

Kross, E., Ayduk, O., \& Mischel, W. (2005). When asking "why" does not hurt: Distinguishing rumination from reflective processing of negative emotions. Psychological Science, 16, 709-715.

Kross, E., Duckworth, A., Ayduk, O., \& Tsukayama, E., \& Mischel, W. (2011). The effect of self-distancing on adaptive vs. maladaptive self-reflection in children. Emotion, 11, 10321039.

Kross, E., Gard, D., Deldin, P., Clifton, J., \& Ayduk, O. (2012). Asking why from a distance: Its cognitive and emotional consequences for people with Major Depressive Disorder. Journal of Abnormal Psychology, 121, 559-569.

Libby, L. K., \& Eibach, R. P. (2002). Looking back in time: Self-concept change affects visual perspective in autobiographical memory. Journal of Personality and Social Psychology, 82, 167-179. 
Luk, K. K. S., Xiao, W. S., \& Cheung, H. (2012). Cultural effect on perspective taking in Chinese-English bilinguals. Cognition, 124, 350-355.

Lyke, J. A. (2009). Insight, but not self-reflection, is related to subjective well-being. Personality and Individual Differences, 46, 66-70.

Mason, W., \& Suri, S. (2012). Conducting behavioral research on Amazon's Mechanical Turk. Behavior Research Methods, 44, 1-23.

Markus, H. R., \& Kitayama, S. (2003). Models of agency: Sociocultural diversity in the construction of action. In V. Murphy-Burman \& J. Berman (Eds.), Nebraska Symposium on Motivation: Vol 49. Cross cultural differences in perspectives on self (pp. 1-57). Lincoln: University of Nebraska Press.

Matsumoto, D., Takeuchi, S., Andayani, S., Kouznetsova, N., \& Krupp, D. (1998). The contribution of individualism vs. collectivism to cross-national differences in display rules. Asian Journal of Social Psychology, 1, 147-165.

Mead, G. H. (1913). The social self. Journal of Philosophy, Psychology and Scientific Methods, 10, 374-380.

Menon, U. (2000). Analyzing emotions as culturally constructed scripts. Culture and Psychology, $6,40-50$.

Mischkowski, D., Kross, E., \& Bushman, B. (2012). Flies on the wall are less aggressive: Selfdistancing "in the heat of the moment" reduces aggressive thoughts, angry feelings and aggressive behavior. Journal of Experimental Social Psychology, 48, 1187-1191.

Miyamoto, Y., Nisbett, R. E., \& Masuda, T. (2006). Culture and the physical environment: Holistic versus analytic perceptual affordances. Psychological Science, 17, 113-119. 
Mor, N., \& Winquist, J. (2002). Self-focused attention and negative affect: A meta-analysis. Psychological Bulletin, 128, 638-662.

Morling, B., Kitayama, S., \& Miyamoto, Y. (2002). Cultural practices emphasize influence in the United States and adjustment in Japan. Personality and Social Psychology Bulletin, 28, $311-323$.

Naumov, A., \& Puffer, S. (2000). Measuring Russian culture using Hofstede's dimensions. Applied Psychology, 49, 709-718.

Nigro, G., \& Neisser (1983). Point of view in personal memories. Cognitive Psychology, 15, 467-482.

Nisbett, R. E., Peng K., Choi, I., \& Norenzayan, A. (2001). Culture and systems of thought: Holistic versus analytic cognition. Psychological Review, 108, 291-310.

Nisbett, R. E. \& Wilson, T. D.(1977). Telling more than we can know: Verbal reports on mental processes. Psychological Review, 84, 231-259.

Nolen-Hoeksema, S., Wisco, B. E., \& Lyubomirsky, S. (2008). Rethinking rumination. Perspectives on Psychological Science, 3, 400-424.

Peng. K., \& Nisbett, R. E. (1999). Culture, dialectics, and reasoning about contradiction. American Psychologist, 54, 741-754.

Pennebaker, J. W. (1997). Writing about emotional experiences as a therapeutic process. Psychological Science, 8, 162-166.

Pennebaker, J. W., Booth, R. J., \& Francis, M. E. (2007). Linguistic Inquiry and Word Count: LIWC [Computer software]. Austin, TX: LIWC.net. 
Pennebaker, J. W., \& Chung, C. K. (2007). Expressive writing, emotion upheavals, and health. In H. S. Friedman \& R. C. Silver (Eds.), Foundations of Health Psychology (pp. 263284). New York: Oxford University Press.

Preacher, K. J., \& Kelley, K. (2011). Effect size measures for mediation models: Quantitative strategies for communicating indirect effects. Psychological Methods, 16, 93-115.

Rozin, P. (2001). Social psychology and science. Personality and Social Psychology Review, 5, $2-14$.

Realo, A., \& Allik, J. (1999). A cross-cultural study of collectivism: A comparison of American, Estonian, and Russian students. Journal of Social Psychology, 139, 133-142.

Ross, M., \& Wilson. A. E. (2002). It feels like yesterday: Self-esteem, valence of personal past experiences, and judgments of subjective distance. Journal of Personality and Social Psychology, 82, 792-803.

Savani, K., Markus, H. R., \& Conner, A. L. (2008). Let your preference be your guide? Preferences and choices are more tightly linked for North Americans than for Indians. Journal of Personality and Social Psychology, 95, 861-876.

Shrout, P. E., \& Bolger, N. (2002). Mediation in experimental and nonexperimental studies: New procedures and recommendations. Psychological Methods, 7, 422-445.

Staudinger, U. M. (2001). Life reflection: A social-cognitive analysis of life review. Review of General Psychology, 5, 148-160.

Smyth, J. M. (1998). Written emotional expression: Effect sizes, outcome types, and moderating variables. Journal of Consulting and Clinical Psychology, 66, 174-184.

Sutin, A. R., \& Robbins, R. W. (2010). Correlates and phenonomenlogy of first and third person memories. Memory, 18, 625-637. 
Tiberius, V. (2008). The reflective Life: Living wisely with our limits. New York: Oxford University Press.

Tower, R. K., Kelly, C., \& Richards, A. (1997). Individualism, collectivism and reward allocation: A cross-cultural study in Russia and Britain. British Journal of Social Psychology, 36, 331-345.

Trapnell, P. D. \& Campbell, J. D. (1999). Private self-consciousness and the five-factor model of personality: Distinguishing rumination from reflection. Journal of Personality and Social Psychology, 76, 284-304.

Treynor, W., Gonzalez, R. \& Nolen-Hoeksema, S. (2003). Rumination reconsidered: A psychometric analysis. Cognitive Therapy and Research, 27, 247-259.

Trope, Y., \& Liberman, N. (2010). Construal-level theory of psychological distance. Psychological Review, 117, 440-463.

Tsai, J. L., Knutson, B., \& Fung, H. H. (2006). Cultural variation in affect valuation. Journal of Personality and Social Psychology, 90, 288-307.

Van Boven, L., Kane, J., McGraw, A. P., \& Dale, J. (2010). Feeling close: Emotional intensity reduces perceived psychological distance. Journal of Personality and Social Psychology, $98,872-885$.

Verduyn, P., Van Mechelen, I., \& Kross, E., Chezzi, C, Van Bever F. (2012). The relationship between self-distancing and the duration of negative and positive emotional experiences in daily life. Emotion, 12, 1248-1263.

Watkins. E. R. (2008). Constructive and unconstructive repetitive thought. Psychological Bulletin, 134, 163-206. 
Watson, D., Clark, L. A., \& Tellegen, A. (1988). Development and validation of brief measures of positive and negative affect: The PANAS scales. Journal of Personality and Social Psychology, 54, 1063-1070.

Wilson, T. D. (2002). Strangers to ourselves: Discovering the adaptive unconscious. Cambridge, MA: Harvard University Press.

Wilson, T. D. (2009). Know thyself. Perspectives on Psychological Science, 4, 384-389.

Wilson, T. D., \& Gilbert, D. T. (2008). Explaining away: A model of affective adaptation. Perspectives on Psychological Science, 3, 370-386.

Wilson, T. D., \& Dunn, E. (2004). Self-knowledge: Its limits, value, and potential for improvement. Annual Review of Psychology, 55, 493-518.

Wisco, B. E. (2009). Depressive cognition: self-reference and depth of processing. Clinical Psychology Review, 29, 382-392.

Wu, S., \& Keysar, B. (2007). The effect of culture on perspective taking. Psychological Science, $18,600-606$. 
Table 1

Descriptive Statistics and Mean Differences for Spontaneous Condition

\begin{tabular}{|c|c|c|c|c|c|}
\hline \multirow[t]{2}{*}{ Variable } & \multicolumn{2}{|c|}{$\begin{array}{l}\text { European American } \\
\qquad(n=47)\end{array}$} & \multicolumn{2}{|c|}{ Indian $(n=46)$} & \multirow[b]{2}{*}{$|d|$} \\
\hline & $M$ & $S D$ & $M$ & $S D$ & \\
\hline Self-Perspective & 5.85 & 1.18 & 5.71 & 1.29 & 0.11 \\
\hline Observer Perspective & 2.00 & 1.27 & $3.22 * *$ & 2.04 & 0.72 \\
\hline Close Other Perspective & 3.49 & 1.82 & $4.33 *$ & 1.91 & 0.45 \\
\hline PA & 2.38 & 0.78 & $3.19 * * *$ & 0.94 & 0.94 \\
\hline NA & 1.87 & 0.68 & 2.10 & 0.85 & 0.30 \\
\hline HAN & 1.88 & 0.87 & 2.07 & 0.87 & 0.22 \\
\hline Emotional Reactivity & 4.51 & 1.48 & 4.69 & 1.45 & 0.12 \\
\hline $\begin{array}{l}\text { Thought Content (Recount - } \\
\text { Reconstrue) }\end{array}$ & 1.51 & 1.65 & $-.19 * * *$ & 1.09 & 1.21 \\
\hline Psychological Distance & 3.48 & 1.51 & 3.38 & 1.47 & 0.07 \\
\hline $1^{\text {st }}$ Person Singular Pronouns & $8.98 \%$ & $4.54 \%$ & $9.92 \%$ & $4.14 \%$ & 0.21 \\
\hline $3^{\text {rd }}$ Person Singular Pronouns & $4.50 \%$ & $3.16 \%$ & $4.75 \%$ & $4.13 \%$ & 0.07 \\
\hline
\end{tabular}

Note. ${ }^{*} p<.05, * * p<.01, * * * p<.001$ 
Table 2

\section{Zero-Order Correlations for Spontaneous Condition}

\begin{tabular}{|c|c|c|c|c|c|c|c|c|c|c|c|c|c|}
\hline Var & iable & 1 & 2 & 3 & 4 & 5 & 6 & 7 & 8 & 9 & 10 & 11 & 12 \\
\hline 1 & $\begin{array}{l}\text { Culture }(1=\text { Indian, } 0= \\
\text { European American })\end{array}$ & -- & -.06 & $.34 * *$ & $.22 * *$ & $.43 * *$ & .15 & .11 & .06 & $-.52 * * *$ & -.03 & .11 & .03 \\
\hline 2 & Self-Perspective & & -- & $-.26^{*}$ & -.15 & -.17 & -.14 & -.15 & .09 & .13 & -.16 & -.15 & -.02 \\
\hline 3 & Observer Perspective & & & -- & $.22 *$ & .16 & $.36 * *$ & $.29 * *$ & .01 & $-.27 *$ & $.26^{*}$ & .06 & $-.24 *$ \\
\hline 4 & Close Other Perspective & & & & -- & $.31 *$ & .01 & -.01 & .01 & -.20 & -.20 & -.09 & -.02 \\
\hline 5 & $\mathrm{PA}$ & & & & & -- & -.06 & -.06 & .18 & $-.39 * * *$ & .03 & -.01 & .01 \\
\hline 6 & NA & & & & & & -- & $.92 * *$ & $.41 * *$ & .02 & .19 & -.04 & -.04 \\
\hline 7 & HAN & & & & & & & -- & $.42 *$ & .06 & $.22 *$ & -.05 & -.05 \\
\hline 8 & Emotional Reactivity & & & & & & & & -- & .14 & .02 & -.04 & .03 \\
\hline 9 & $\begin{array}{l}\text { Thought Content (Recount - } \\
\text { Reconstrue) }\end{array}$ & & & & & & & & & -- & -.08 & -.12 & .12 \\
\hline 10 & Psychological Distance & & & & & & & & & & -- & .14 & -.05 \\
\hline 11 & $1^{\text {st }}$ Person Singular Pronouns & & & & & & & & & & & -- & .10 \\
\hline 12 & $3^{\text {rd }}$ Person Singular Pronouns & & & & & & & & & & & & -- \\
\hline
\end{tabular}

Note. $* p<.05, * * p<.01, * * * p<.001$. 
Table 3

Standardized Parameter Estimates from Multiple Regression Analyses for Spontaneous Condition

\begin{tabular}{lcccc}
\hline & \multicolumn{4}{c}{ Predictor } \\
\cline { 2 - 5 } \multicolumn{1}{c}{ Dependent Variable } & Culture & Self- & Observer & Close Other \\
PA & & Perspective & Perspective & Perspective \\
NA & $.39 * * *$ & -.13 & -.05 & $.22^{*}$ \\
HAN & .05 & -.07 & $.33^{* * *}$ & -.09 \\
Emotional Reactivity & .03 & -.10 & $.26^{*}$ & -.09 \\
Thought Content (Recount - & $-.48^{* * *}$ & .08 & -.07 & .00 \\
Reconstrue) & & & .00 & -.07 \\
Psychological Distance & -.09 & -.12 & $.32 * *$ & $-.26^{*}$ \\
$1^{\text {st }}$ Person Singular Pronouns & .12 & -.16 & .00 & -.15 \\
$3^{\text {rd }}$ Person Singular Pronouns & .13 & -.10 & $-.33^{* *}$ & .00 \\
\hline
\end{tabular}

Note. $* p<.05, * * p<.01, * * * p<.001$. 
Table 4

Model Coefficients for Spontaneous Condition

\begin{tabular}{|c|c|c|c|c|c|c|c|}
\hline \multirow[b]{2}{*}{ Predictor } & \multirow[b]{2}{*}{ Mediator } & \multirow[b]{2}{*}{ Outcome } & \multicolumn{5}{|c|}{ Effect } \\
\hline & & & $a$ & $b$ & $c^{\prime}$ & $a b$ & $c$ \\
\hline Culture & $\begin{array}{l}\text { Close Other } \\
\text { Perspective }\end{array}$ & $\mathrm{PA}$ & $.84(.39)[.07,1.60]$ & $.12(.05)[.02, .21]$ & $.72(.18)[.36,1.07]$ & $.10(.06)[.01, .27]$ & $.81(.18)[.45,1.17]$ \\
\hline Culture & $\begin{array}{l}\text { Observer } \\
\text { Perspective }\end{array}$ & $\begin{array}{l}\text { Thought } \\
\text { Content }\end{array}$ & $1.22(.35)[.52,1.92]$ & $-.09(.09)[-.26, .08]$ & $-1.58(.31)[-2.19,-.97]$ & $-.11(.10)[-.37, .05]$ & $-1.69(.29)[-2.27,-1.12]$ \\
\hline Culture & $\begin{array}{l}\text { Thought } \\
\text { Content }\end{array}$ & PA & $-1.69(.29)[-2.27,-1.12]$ & $-.14(.06)[-.26,-.01]$ & $.58(.21)[.17, .99]$ & $.23(.13)[.01, .49]$ & $.81(.18)[.45,1.17]$ \\
\hline
\end{tabular}

Note. Estimates are unstandardized. Culture was coded as $1=$ Indian, $0=$ European American. Parentheses contain $S E$ for coefficients.

Brackets contain $95 \%$ confidence intervals. Confidence intervals for indirect effect $a b$ are based on 5000 bias-corrected bootstrap samples using analytic framework PROCESS (Hayes, 2013). 
Table 5

Model Coefficients for Experimentally Manipulated Conditions

\begin{tabular}{|c|c|c|c|c|c|c|c|}
\hline \multirow[b]{2}{*}{ Predictor } & \multirow[b]{2}{*}{ Mediator } & \multirow[b]{2}{*}{ Outcome } & \multicolumn{5}{|c|}{ Effect } \\
\hline & & & $a$ & $b$ & $c^{\prime}$ & $a b$ & $c$ \\
\hline Culture & $\begin{array}{l}\text { Thought } \\
\text { Content }\end{array}$ & PA & $-1.36(.18)[-1.71,-1.01]$ & $-.10(.03)[-.16,-.04]$ & $.73(.10)[.52, .93]$ & $.13(.04)[.05, .23]$ & $.86(.10)[.67,1.05]$ \\
\hline Culture & $\begin{array}{l}\text { Thought } \\
\text { Content }\end{array}$ & NA & $-1.36(.18)[-1.71,-1.01]$ & $.08(.03)[.02, .14]$ & $.66(.10)[.46, .86]$ & $-.11(.04)[-.20,-.04]$ & $.55(.09)[.36, .73]$ \\
\hline Culture & $\begin{array}{l}\text { Thought } \\
\text { Content }\end{array}$ & HAN & $-1.36(.18)[-1.71,-1.01]$ & $.11(.03)[.05, .18]$ & $.78(.11)[.56, .99]$ & $-.15(.05)[-.25,-.07]$ & $.62(.10)[.42, .83]$ \\
\hline Culture & $\begin{array}{l}\text { Thought } \\
\text { Content }\end{array}$ & $\begin{array}{l}\text { Emotional } \\
\text { Reactivity }\end{array}$ & $-1.36(.18)[-1.71,-1.01]$ & $.42(.05)[.33, .52]$ & 1.25 (.16) [.93, 1.57] & $-.58(.10)[-.78,-.40]$ & $.67(.17)[.34,1.00]$ \\
\hline
\end{tabular}

Note. Estimates are unstandardized. Culture was coded as $1=$ Indian, $0=$ European American. Parentheses contain $S E$ for coefficients.

Brackets contain $95 \%$ confidence intervals. Confidence intervals for indirect effect $a b$ are based on 5000 bias-corrected bootstrap samples using analytic framework PROCESS (Hayes, 2013). 


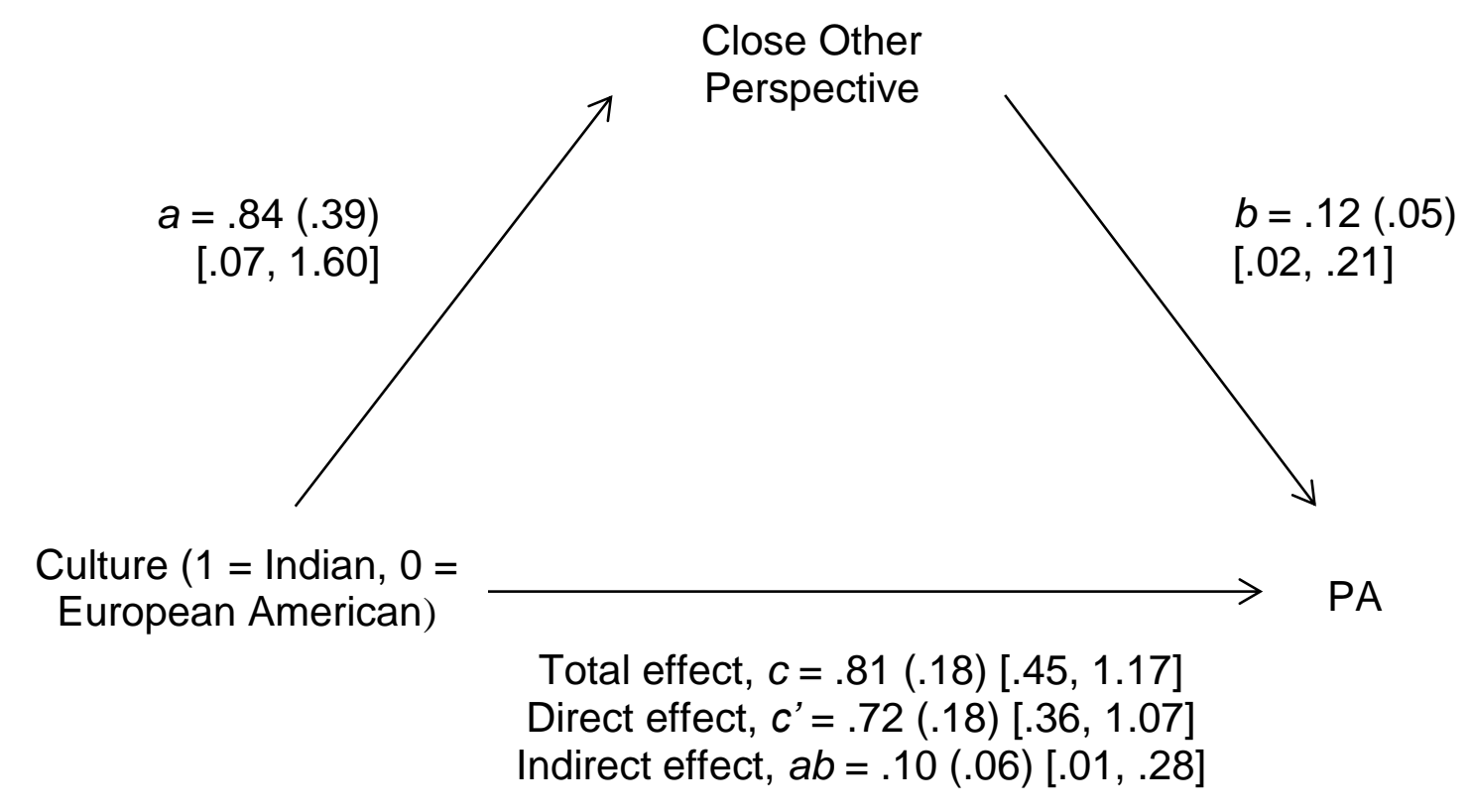

Figure 1. Path analysis examining the role of close other perspective in mediating the effect of culture on PA, for participants in Spontaneous Condition. Coefficients shown are unstandardized, with $95 \%$ CI in brackets. Parentheses indicate $S E$ of coefficient. 


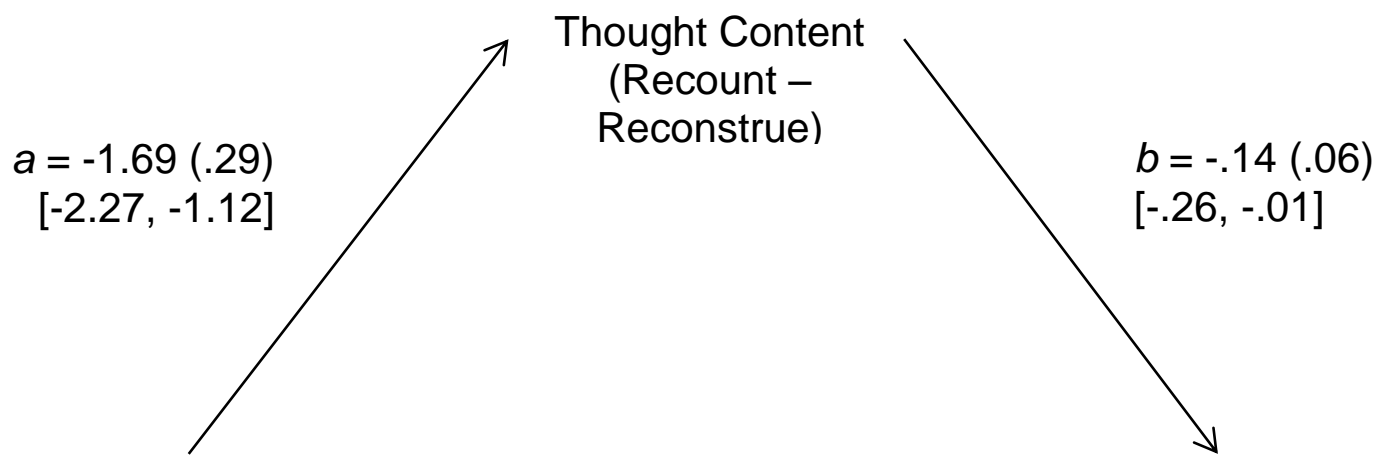

Culture $(1=$ Indian, $0=$ European American)

Total effect, $c=.81(.18)[.45,1.17]$

Direct effect, $c^{\prime}=.58(.21)[.17, .99]$

Indirect effect, $a b=.23(.13)[.01, .49]$

Figure 2. Path analysis examining the role of thought content in mediating the effect of culture on PA, for participants in Spontaneous Condition. Coefficients shown are unstandardized, with 95\% CI in brackets. Parentheses indicate $S E$ of coefficient. 


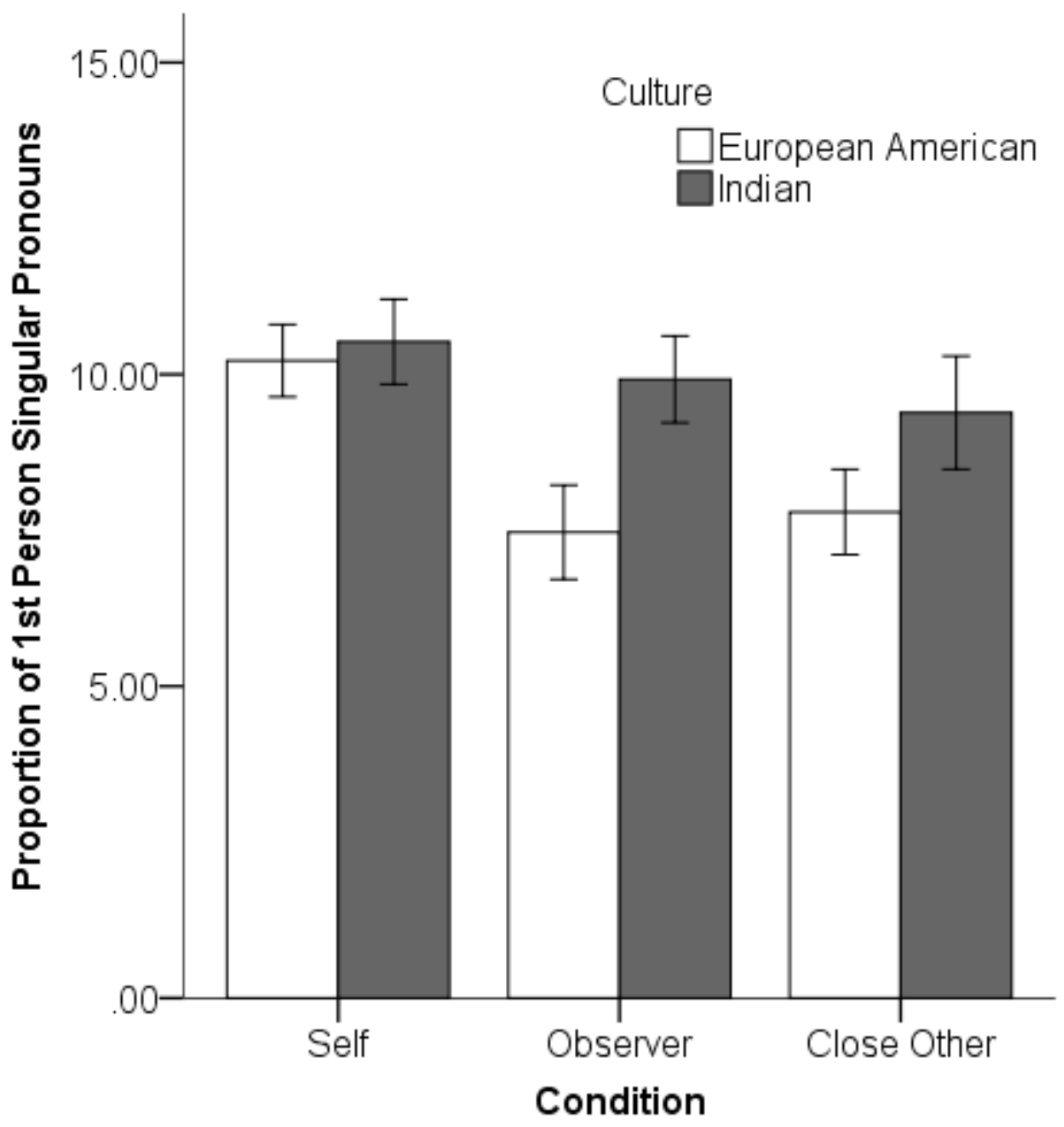

Figure 3. The effect of Culture and Condition on proportion of $1^{\text {st }}$ person singular pronouns for participants in experimentally manipulated conditions. Error bars indicate $S E$. 


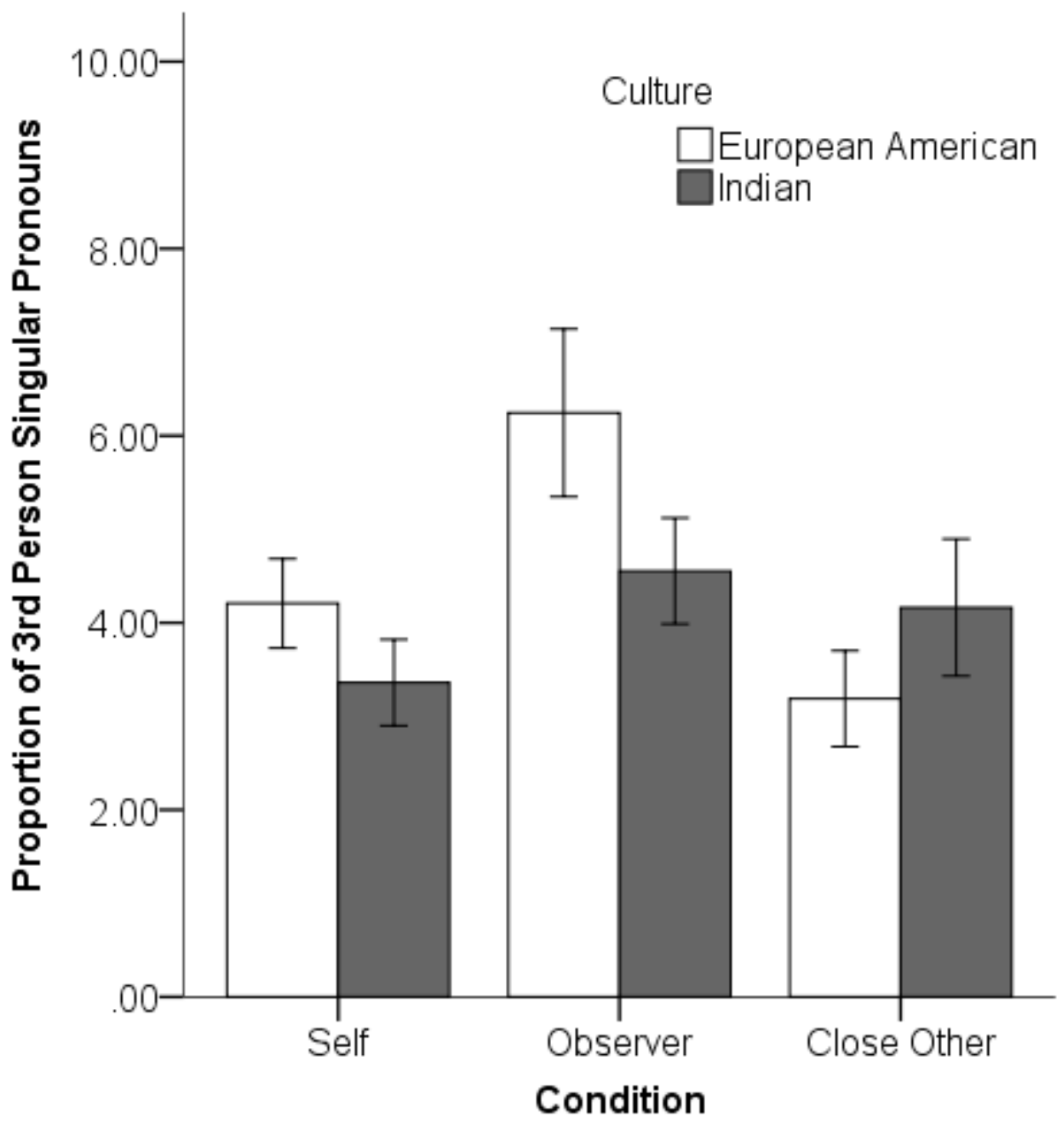

Figure 4. The effect of Culture and Condition on proportion of $3^{\text {rd }}$ person singular pronouns for participants in experimentally manipulated conditions. Error bars indicate $S E$. 


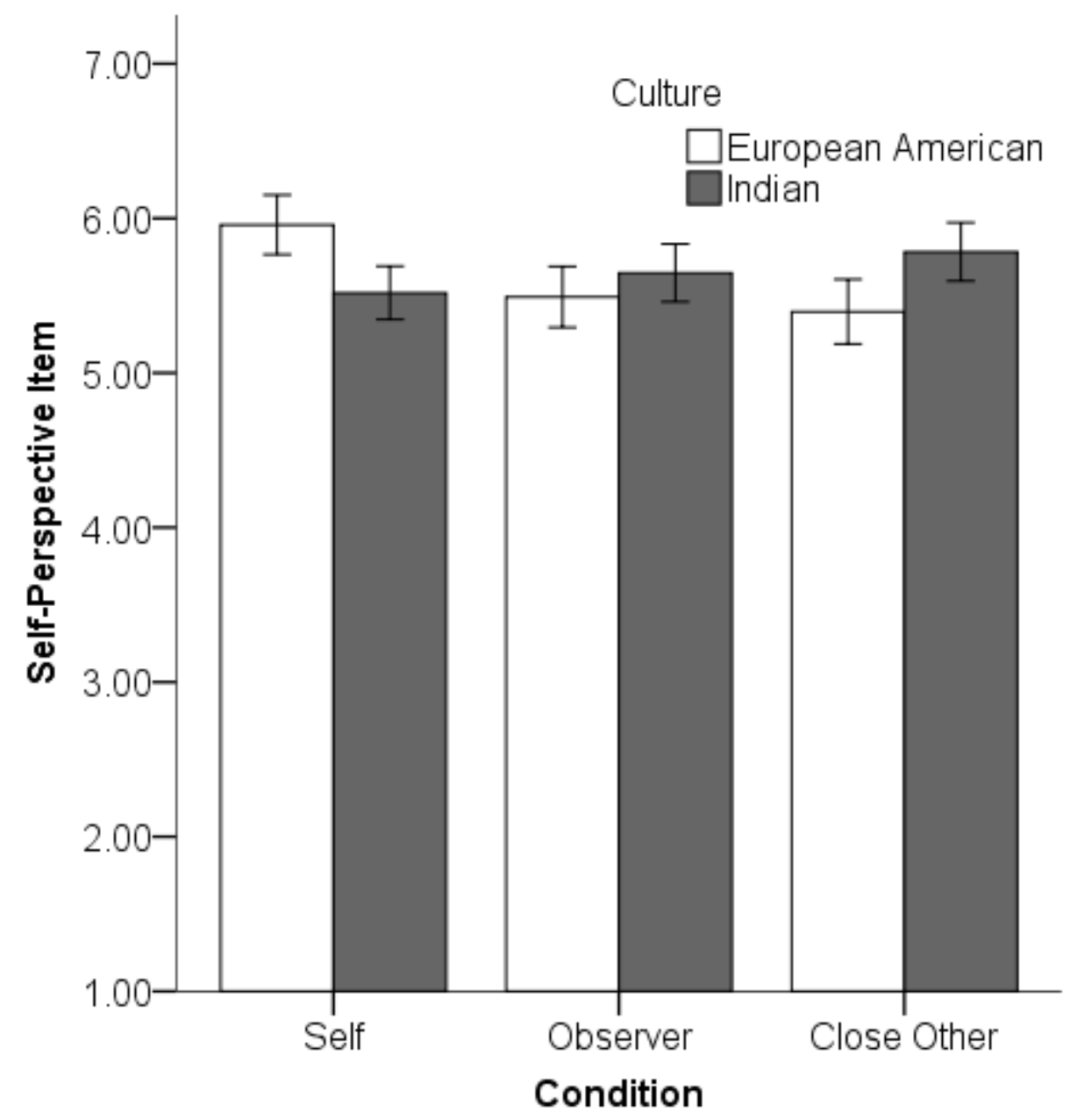

Figure 5. The effect of Culture and Condition on endorsement of self-perspective item for participants in experimentally manipulated conditions. Error bars indicate $S E$. 


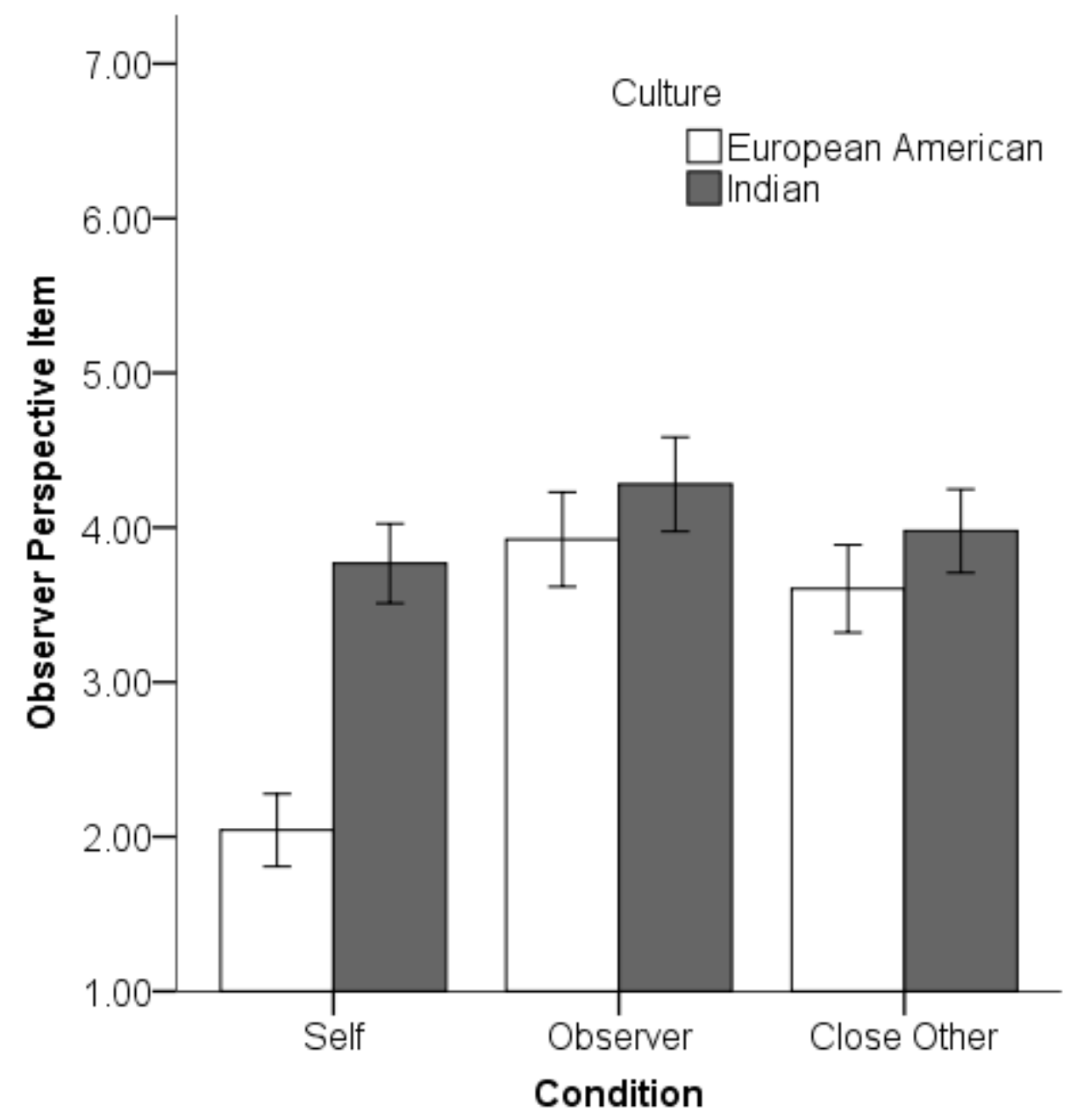

Figure 6. The effect of Culture and Condition on endorsement of observer perspective item for participants in experimentally manipulated conditions. Error bars indicate $S E$. 


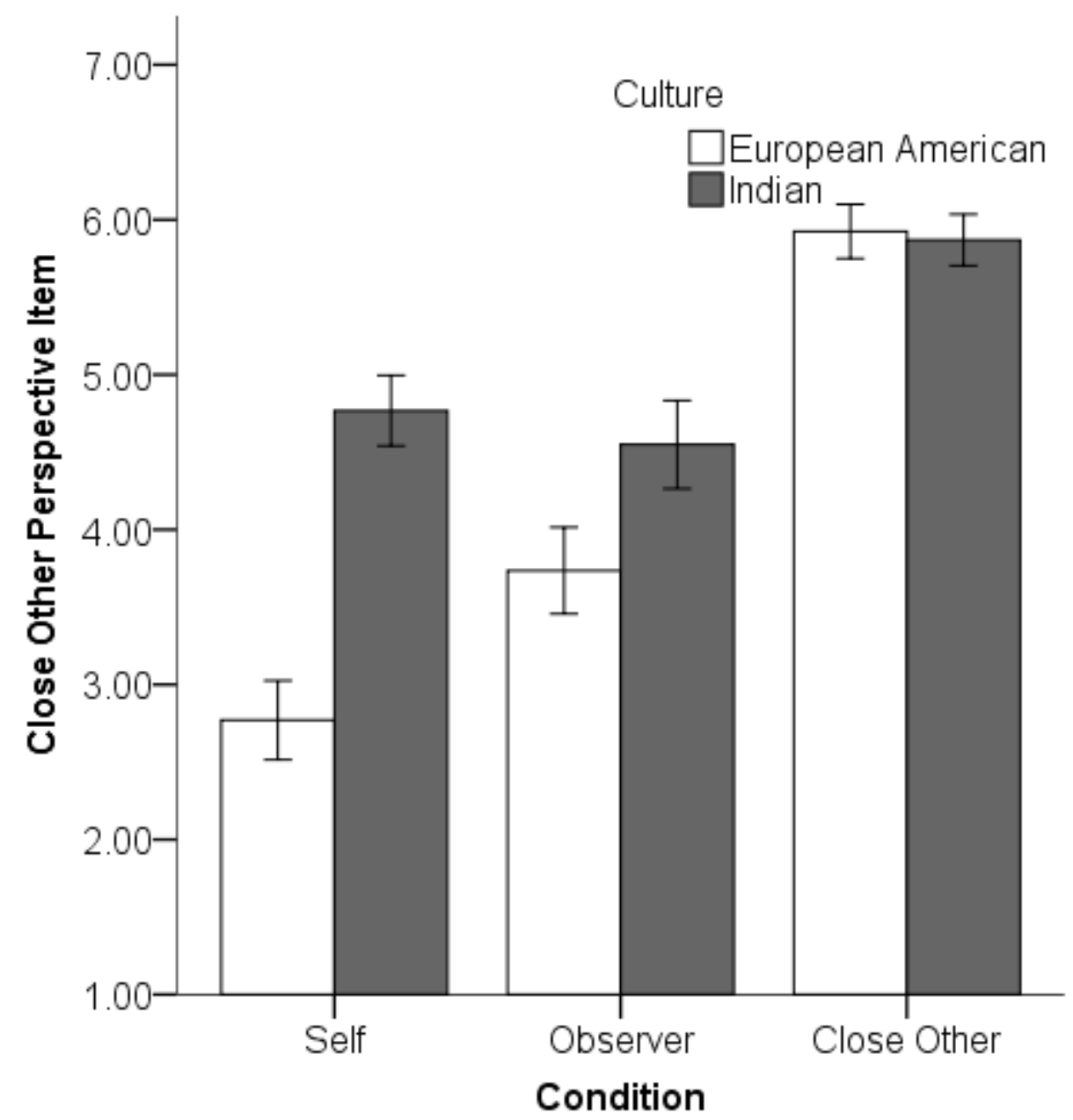

Figure 7. The effect of Culture and Condition on endorsement of close other perspective item for participants in experimentally manipulated conditions. Error bars indicate $S E$. 


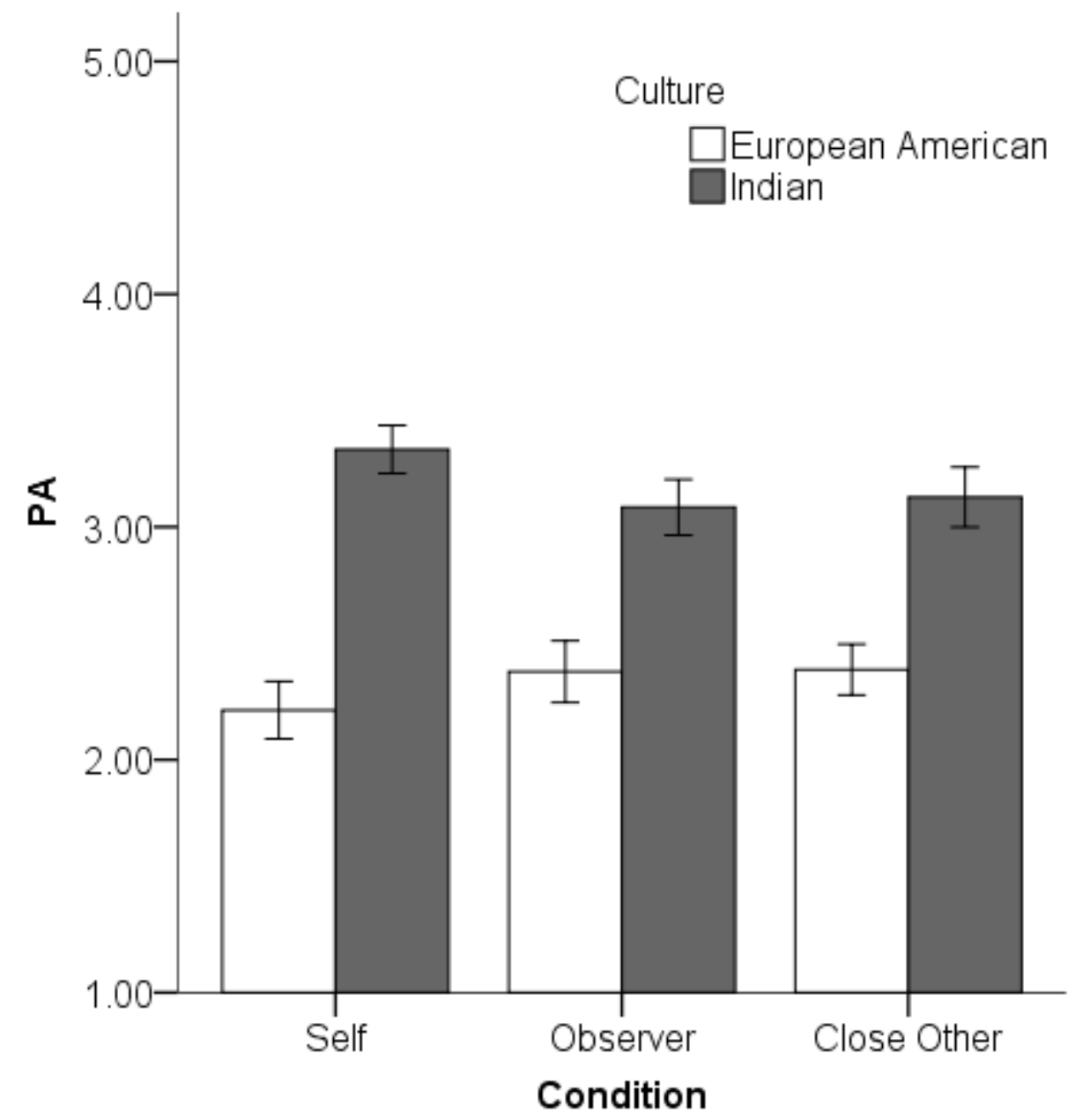

Figure 8. The effect of Culture and Condition on PA for participants in experimentally manipulated conditions. Error bars indicate $S E$. 


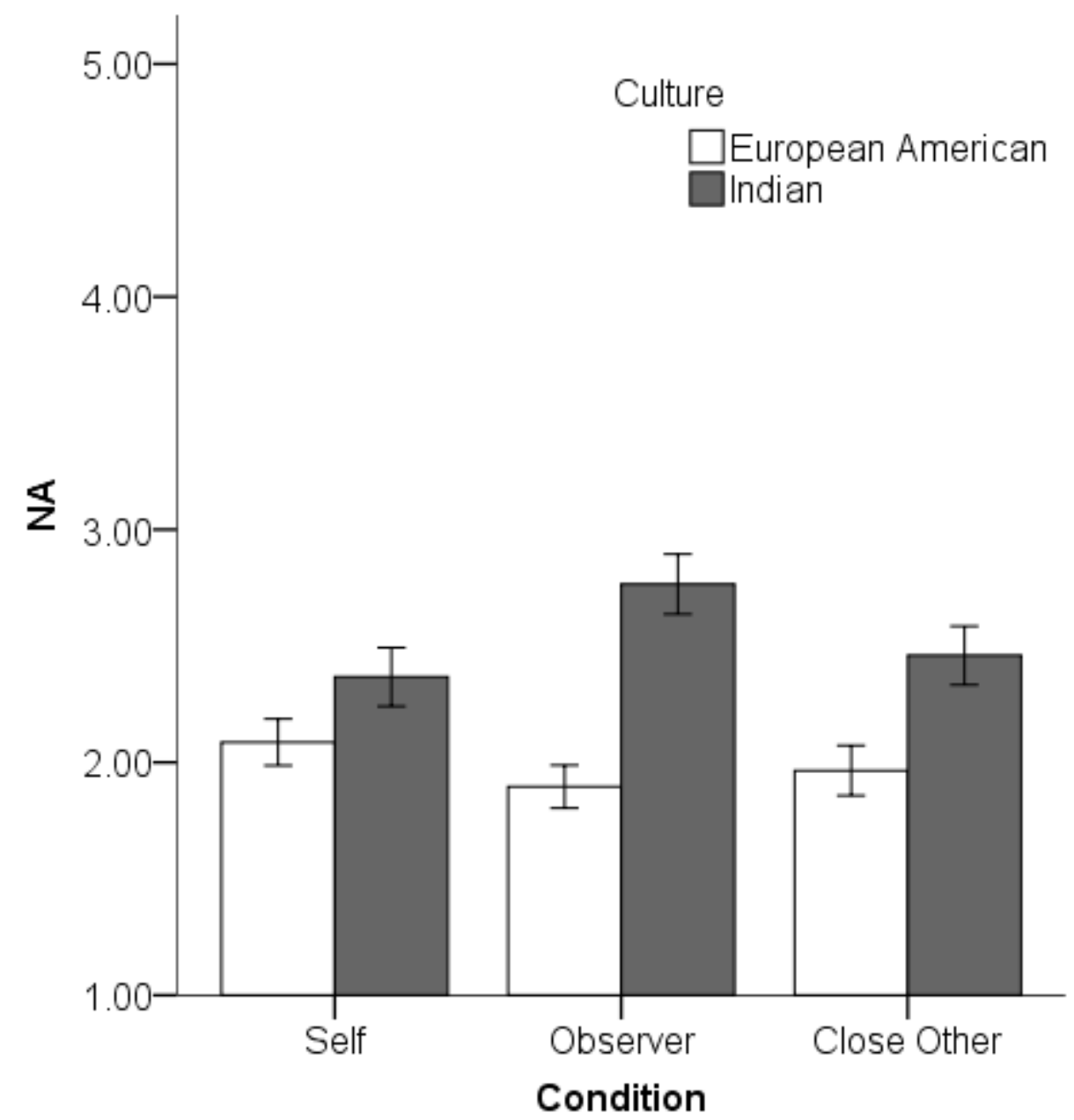

Figure 9. The effect of Culture and Condition on NA for participants in experimentally manipulated conditions. Error bars indicate $S E$. 


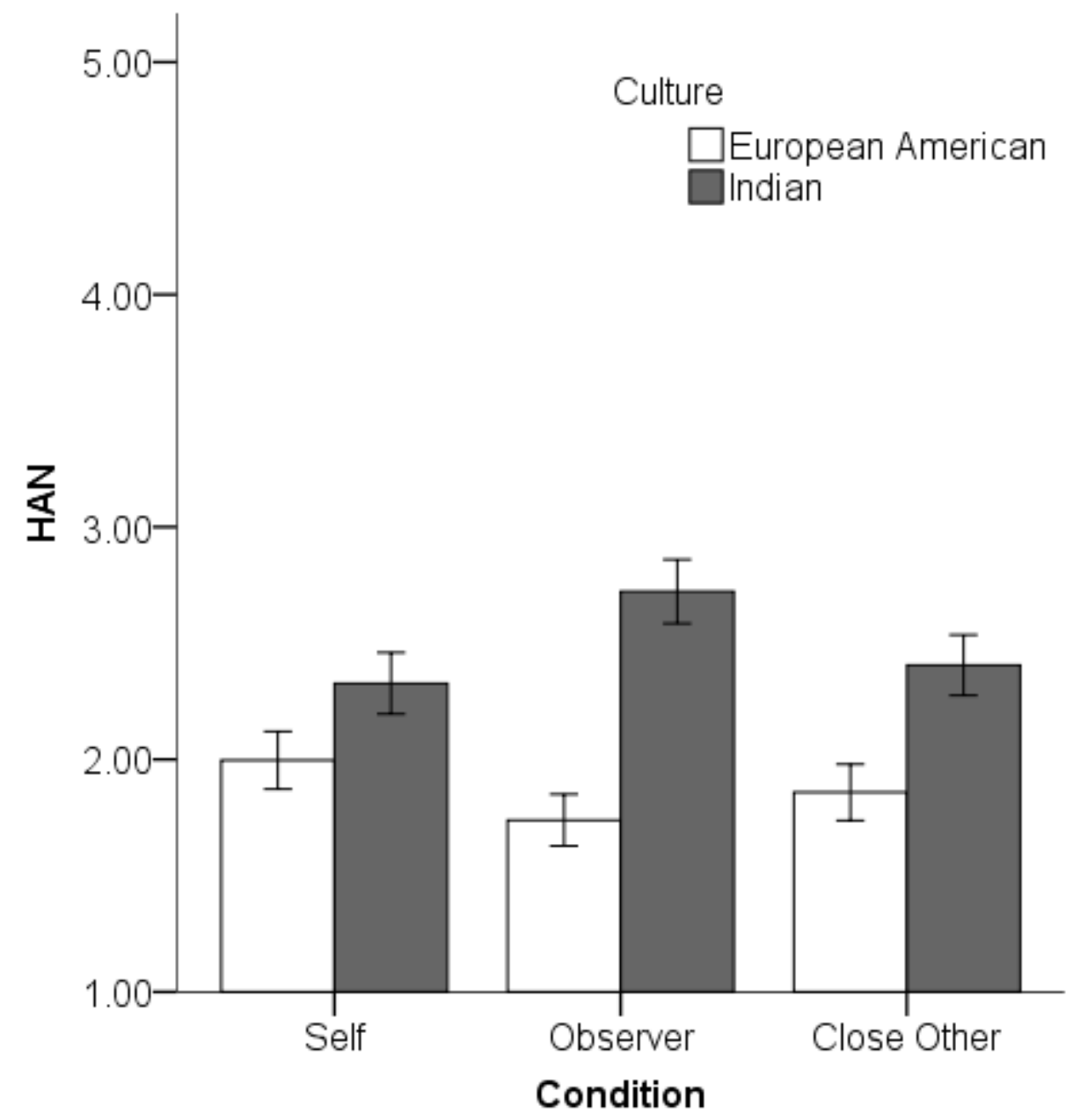

Figure 10. The effect of Culture and Condition on HAN for participants in experimentally manipulated conditions. Error bars indicate $S E$. 


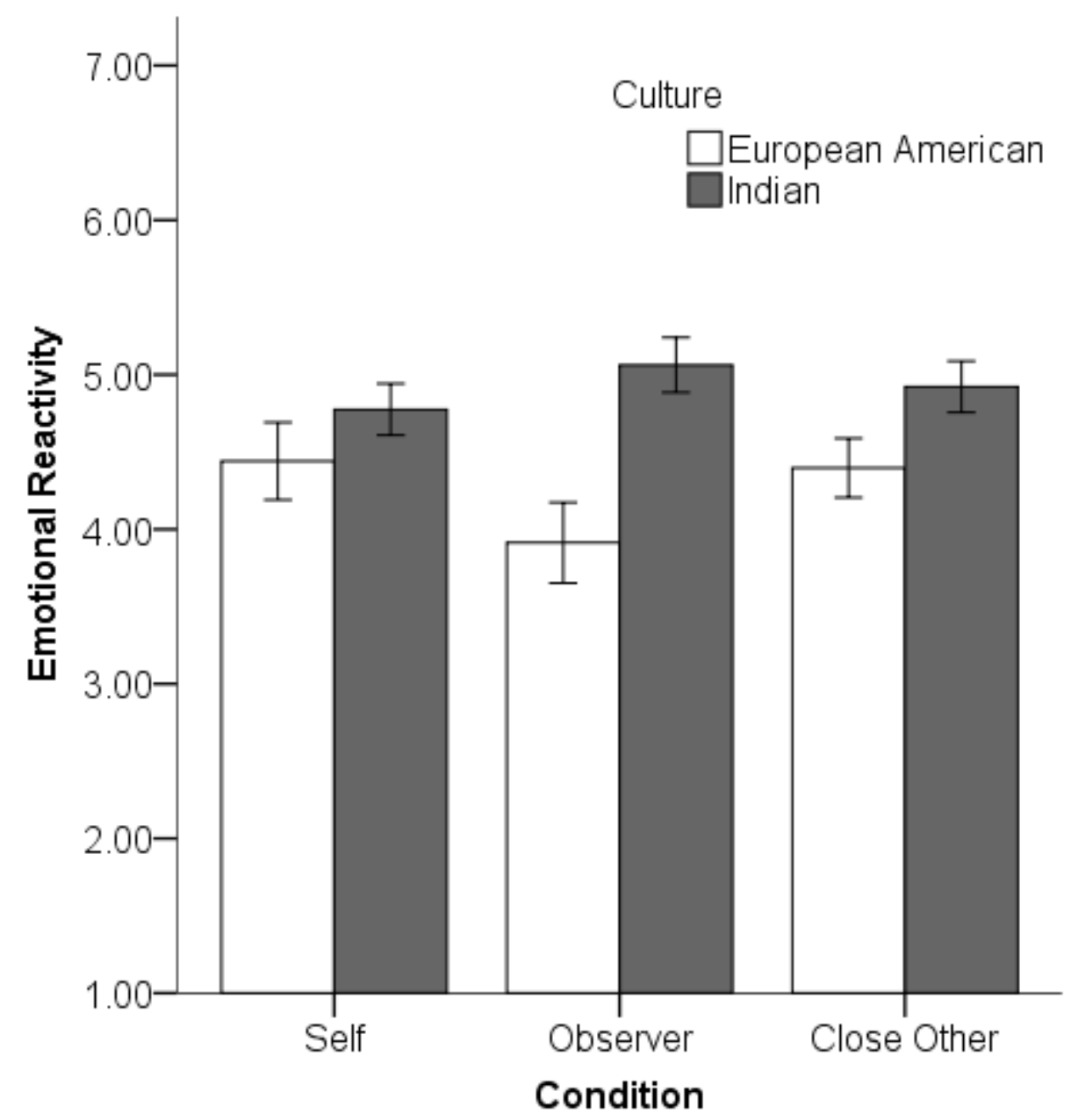

Figure 11. The effect of Culture and Condition on emotional reactivity for participants in experimentally manipulated conditions. Error bars indicate $S E$. 


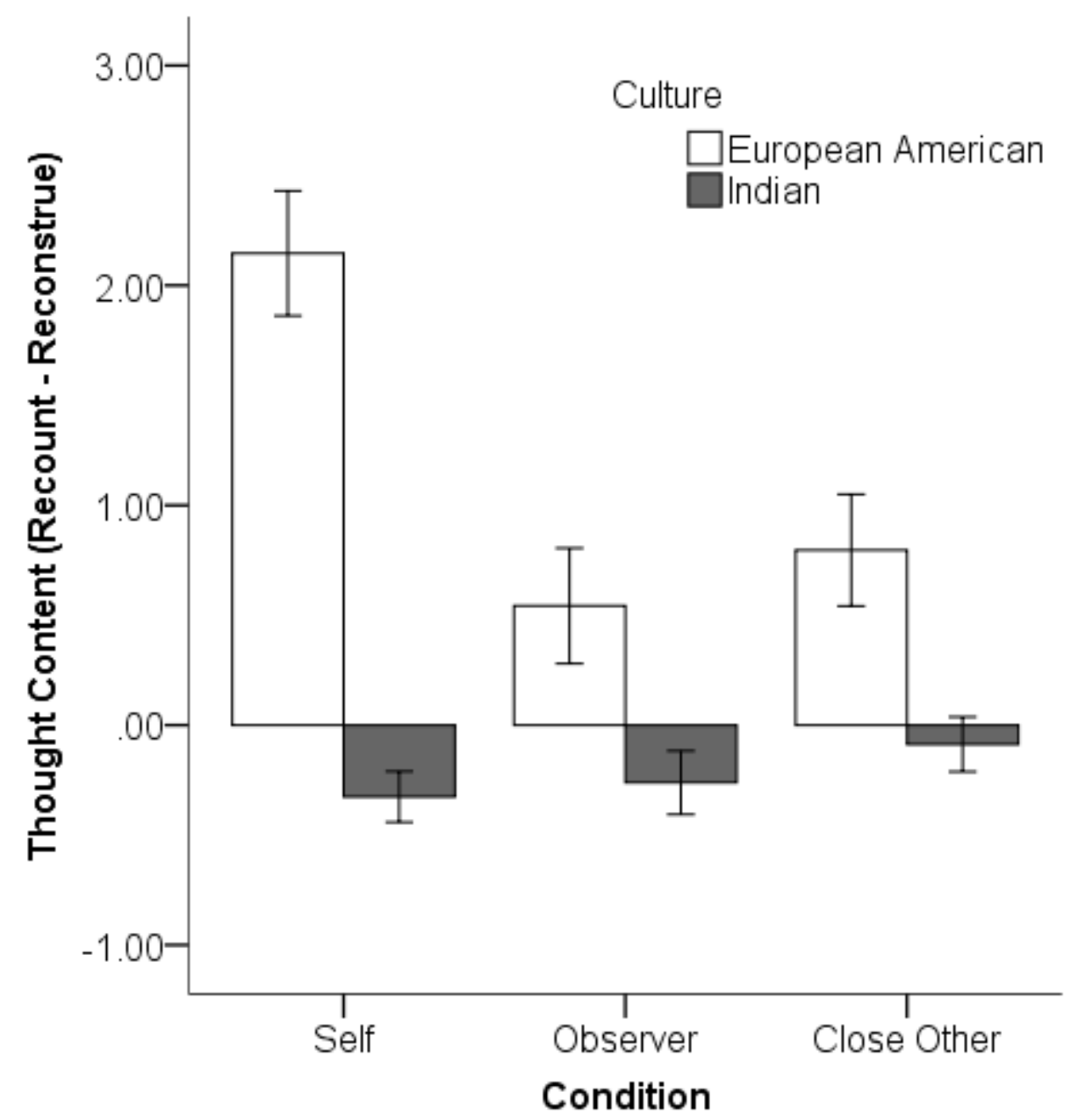

Figure 12. The effect of Culture and Condition on thought content (recount - reconstrue) for participants in experimentally manipulated conditions. Error bars indicate $S E$. 


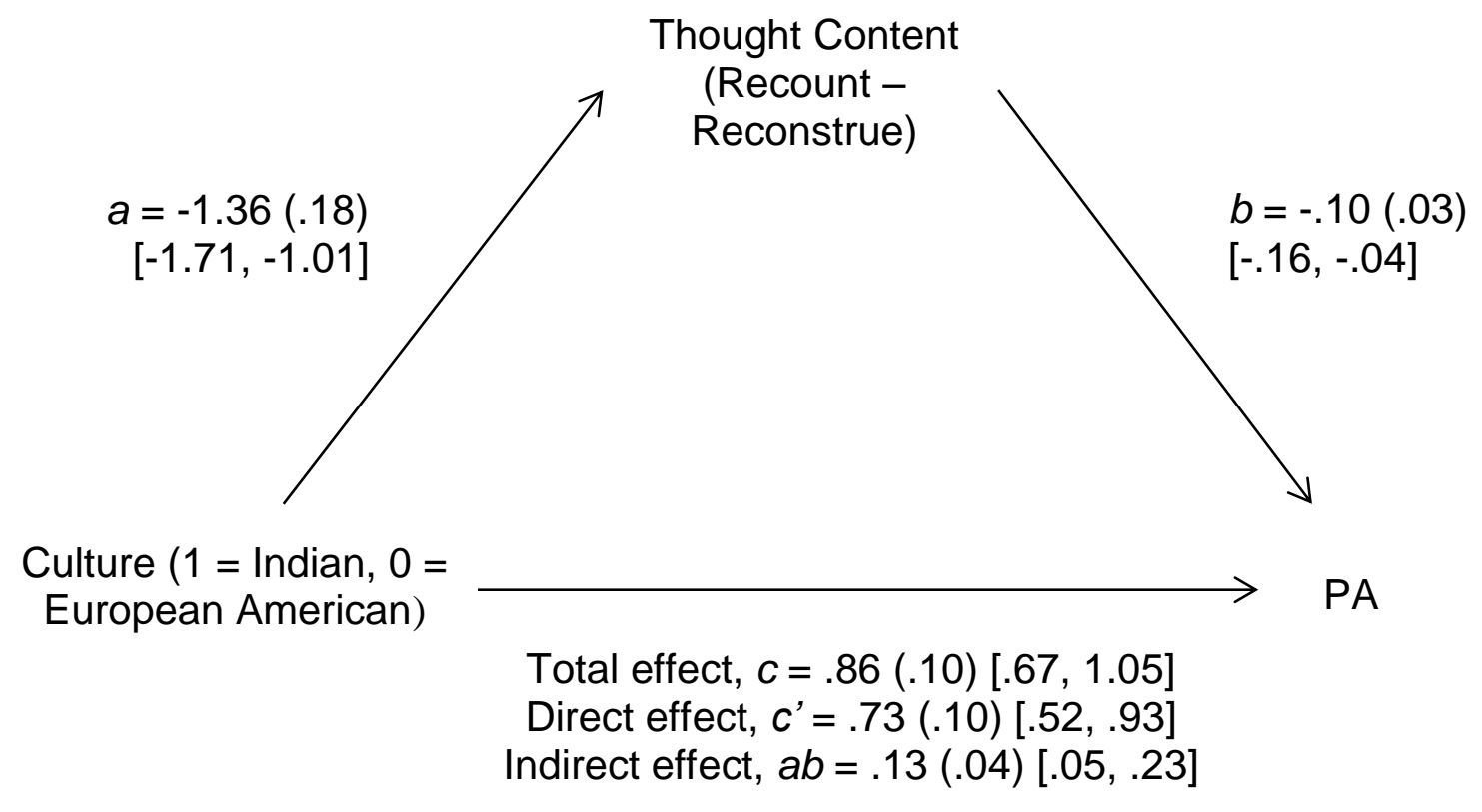

Figure 13. Path analysis examining the role of thought content (recount - reconstrue) in mediating the effect of culture on PA, for participants in Experimentally Manipulated Conditions. Coefficients shown are unstandardized, with $95 \%$ CI in brackets. Parentheses indicate SE of coefficient. 